\title{
El Plan de Recuperación de la UE. Oportunidades para las Administraciones locales
}

\author{
Serafín PAZOS VIDAL* \\ Doctor en Unión Europea \\ Convención de Autoridades Locales Escocesas
}

\begin{abstract}
RESUMEN
El llamado Plan de Recuperación "Next Generation EU» y en concreto su Mecanismo de Recuperación y Resiliencia (MRR) ha generado una enorme expectativa en España, incluido para las Administraciones locales, tanto como oportunidad de una salida rápida a la crisis económica generada por la covid-19 como una oportunidad histórica de acometer grandes reformas estructurales pendientes. Sin embargo, no es en absoluto la primera vez que se aborda este tema, habida cuenta de tres décadas de programas estatales, autonómicos y locales de Fondos Estructurales de la UE. El propio MRR, que suma el doble tamaño que los fondos de cohesión tradicionales, no tiene su origen en la crisis de 2020. La pandemia multiplicó exponencialmente el tamaño de un programa de reformas estructurales preexistente. Al mismo tiempo el Plan Nacional de Recuperación y Resiliencia (España Puede) promete invertir grandes sumas del MRR en el nivel local. Usando los trabajos de la Mesa Nacional Técnica de Diputaciones se examinarán las posibilidades y limitaciones de gestionar en la práctica desde el nivel local los Fondos Estructurales y el MRR para combatir el reto demográfico.
\end{abstract}

Palabras clave: Next Generation EU; despoblación; diputaciones; Plan de Recuperación; covid-19.

\section{ABSTRACT}

The so-called "Next Generation EU» Recovery Plan and specifically its Recovery and Resilience Mechanism (MRR) has generated enormous expectations in Spain, including

* El autor gustaría agradecerle a D. Rafael JimÉnEZ AsEnSIO, Dña. Ana Isabel SÁnChEZ IgLESIAS, D. Jean Christophe García-Baquero Lavezzi, D. Gustavo López Cutillas y D. Thomas Wobben las amables aportaciones y sugerencias recibidas a lo largo de la elaboración de este trabajo. 
for Local Administrations, as well as an opportunity for a quick way out of the economic crisis generated by the covid-19 as a historic opportunity to undertake major pending structural reforms. However, this is by no means the first time that this issue has been addressed, taking into account three decades of state, regional and local EU Structural Fund programmes. The MRR itself, which is twice the size of traditional cohesion funds, does not originate in the 2020 crisis. The pandemic exponentially multiplied the size of a preexisting structural reform program. At the same time, the National Recovery and Resilience Plan ("España Puede») promises to invest large amounts of the MRR at the local level. Using the work of the Technical National Board of Provincial Councils, the possibilities and limitations of managing the Structural Funds and the MRR in practice from the local level to combat the demographic challenge will be examined.

Keywords: Next Generation EU; depopulation; Provincial Councils; Recovery Plan, covid-19.

SUMARIO: I. INTRODUCCIÓN.-II. GÉNESIS DEL PLAN DE RECUPERACIÓN.-III. LAS REFORMAS ESTRUCTURALES Y LA POLÍTICA DE COHESIÓN.-IV. EL MECANISMO DE RECUPERACIÓN Y RESILIENCIA.-V. EL «PLAN ESPAÑA PUEDE» Y EL REAL DECRETOLEY 36/2020, DE 30 DE DICIEMBRE: 1. El Real Decreto-ley 36/2020: un instrumento insuficiente e incompleto.-VI. LA DIMENSIÓN LOCAL DEL PLAN DE RECUPERACIÓN: 1. El ejemplo de la Mesa Nacional Técnica de Diputaciones.-VII. CONCLUSIONES: PERSPECTIVAS DE LAS ADMINISTRACIONES LOCALES EN LOS FONDOS EUROPEOS POST 2020.-VIII. BIBLIOGRAFÍA.

\section{INTRODUCCIÓN}

Desde bien al principio de la crisis de la covid-19 las Administraciones locales demandaron un apoyo específico para evitar la repetición de la crisis de hace una década (Documento FEMP 2020). En el primer semestre de 2020 el desconcierto ante la primera ola de una enfermedad desconocida, la descoordinación inicial de los socios comunitarios, así como en el seno de los mismos, llevo a la propuesta y aprobación en un tiempo récord del llamado plan Next Generation EU (NGEU) ${ }^{1}$ que con sus 750.000 millones para 2021-2006 es tres cuartas partes del tamaño (y a mayores) del presupuesto ordinario de la UE 2021-2027, el llamado Marco Financiero Plurianual (MFP), que entonces también se estaba negociando ${ }^{2}$. El NGEU, estructurado en varios elementos fundamentalmente el REACT $\mathrm{UE}^{3}$ (una especie de fondos estructurales suplementarios

1 Técnicamente se denomina Instrumento de Recuperación Europeo, cfr. Council Regulation (EU) 2020/2094 of 14 December 2020 establishing a European Union Recovery Instrument to support the recovery in the aftermath of the covid-19 crisis.

2 S. PAZOS VIDAL, «El coronavirus como test de resistencia de la integración europea: límites del diálogo constitucional», Eunomía: Revista en Cultura de la Legalidad, núm. 19, 2020, pp. 154-183.

3 Reglamento (UE) 2020/2221, del Parlamento y del Consejo, de 23 de diciembre, por el que se modifica el Reglamento (UE) núm. 1303/2013 en lo que respecta a los recursos adicionales y las disposiciones de 
a los tradicionales) y fundamentalmente el Mecanismo de Recuperación y Resiliencia (MRR) más que doblan el tamaño de los fondos tradicionales destinados al desarrollo regional y local, los Fondos Estructurales y de Inversión Europeos (FEIE), coloquialmente conocidos como Fondos de Cohesión o Política Regional y Urbana de la UE. Por tanto, habrá en los próximos seis o siete años una cantidad ingente de recursos públicos y buena parte de estos pueden beneficiar directamente a las Administraciones locales.

Sin embargo, en el caso español se han creado expectativas exageradas como bálsamo fierabrás de la crisis en ciernes: ni los fondos son a fondo perdido para financiar gasto corriente (como inicialmente querría España o Italia), ni son de gasto inmediato (el MRR deben pedirse entre 2021 y 2023 y el gasto hacerse hasta 2026, y la Comisión Europea reembolsará el gasto que deberá ser efectuado previamente con los recurso de las propias administraciones), sino para acometer inversiones transformadoras a escala de país con vistas al medio plazo.

Tampoco el MRR es en sí una novedad que surge por la covid-19 ya que la Comisión llevaba años intentando incentivar reformas estructurales al margen de los Fondos Estructurales ya existentes, que por cierto valen para financiar casi las mismas actividades. Antes al contrario, el MRR se dispensa de la arquitectura institucional y territorial de los Fondos Estructurales (programas operativos regionales, principio de "partenariado» o asociación), a no ser que los gobiernos voluntariamente decidan mantenerla.

A todo esto se suma el gran retraso en la ejecución de los Fondos Estructurales 2014-2020 y la necesidad de preparar los nuevos programas operativos de dichos Fondos 2021-2027, si bien la atención política y pública está centrada exclusivamente en la novedad del MRR, si bien a diferencia de los Fondos Estructurales, que son asignaciones fijas a siete años de las arcas de los Estados miembros contribuyentes netos a aquellos que son beneficiarios, el NGEU se financiará endeudándose la Comisión en los mercados financieros y en función de la necesidad que vaya habiendo para reembolsar proyectos ya ejecutados ${ }^{4}$.

No estamos en un nuevo 1986 con la llegada del maná europeo, aunque esa es la impresión, dada la proliferación de opinión pública y publicada por el tema, además de la profusión de cursos y seminarios y consultorías al respecto. Y esto es bueno ya que podemos aprender de tres décadas de gestión de fondos europeos.

En el caso de España, en el momento de redactar este artículo solo tenemos, aparte del Reglamento del MRR y la guía que lo acompaña, un puñado de documentos oficiales de referencia: el borrador del llamado «Plan España Puede» oficialmente el Plan Nacional de Recuperación y Resiliencia, que establece las prioridades de gasto, y que

ejecución a fin de prestar asistencia para favorecer la reparación de la crisis en el contexto de la pandemia de covid-19 y sus consecuencias sociales y para preparar una recuperación verde, digital y resiliente de la economía (REACT UE).

4 R. XIFRÉ, «El plan NGEU en España: retos estructurales y revisión de propuestas», Cuadernos de Información Económica, núm. 279, 2020, pp. 11-20. 
debe de ser finalizado para presentar a la Comisión para su aprobación antes de finales de abril de 2020 - y el muy comentado y anticipado Real Decreto-ley 36/2020, de 30 de diciembre, que introduce los parámetros principales de la gestión del MRR en España y de la gestión del mismo- - Si bien esto es difícilmente comparable con la profusión de documentos estratégicos y legislativos que define (según sus redactores, ralentiza) la programación, gestión y evaluación de los Fondos Estructurales, ya que permite establecer las continuidades y diferencia con los Fondos Estructurales tradicionales.

Para ilustrar el posible rol de las Administraciones locales se resume el ejercicio de análisis y prospectiva sobre la adecuación de los Fondos Estructurales 2021-2027 y el MRR a las necesidades y experiencia de las Administraciones locales realizado por la llamada Mesa Nacional Técnica de Diputaciones, convocada por la diputación de Zamora y facilitada por este autor entre octubre y diciembre de 2020 y que ha resultado en un documento común de propuestas de buena parte de las diputaciones de España respecto a las convocatorias de los ministerios para el MRR, así como los Programas Operativos clásicos de las autonomías.

Tras esta introducción, este artículo se estructura de la siguiente manera: génesis del plan de recuperación de la UE, antecedentes, el Mecanismo de Recuperación y Resiliencia, el plan de recuperación español, y el posible impacto a nivel local basándonos en los recientes trabajos de la llamada Mesa Nacional Técnica de Diputaciones, para finalmente extraer una serie de conclusiones preliminares.

\section{GÉNESIS DEL PLAN DE RECUPERACIÓN}

Para entender cuál puede ser el papel de las Administraciones locales respecto al MRR hay que ir más allá de la covid-19 y que contextualizar su surgimiento en el contexto del Semestre Europeo - el proceso de negociador anual entre Estados miembros y Comisión sobre reformas estructurales en el aspecto macroeconómico-fiscal y de políticas y servicios públicos- y la relación o falta de la misma entre el MRR y los Fondos Estructurales clásicos en los que dichas Administraciones son ya protagonistas.

Durante la primavera de 2020 se confirmó una vez más el adagio de que la UE se crece en las crisis. En el espacio de unas semanas y dado el pánico a que la covid-19 abocase a la UE a una nueva crisis como la financiera de 2008 y la de la eurozona durante buena parte los nuevos años veinte, temas tabús dejaron de ser hipótesis largamente debatidas a una realidad: como la mutualización de la deuda ${ }^{5}$, y con ellas, la posibilidad de la Comisión Europea dotarse de recursos propios, vía impuestos europeos y no como ahora vía las arcas de los Estados miembros ${ }^{6}$. Este proceso culminó en el excepcional-

5 M. KÖLLING, «El Consejo Europeo extraordinario del 17 al 20 de julio de 2020: mucho ruido, muchas nueces y algunas sombras», Análisis del Real Instituto Elcano (ARI), núm. 100, 2020.

${ }^{6}$ D. LÓPEZ GARRIDO, «La silenciosa constitucionalización de la Unión Europea», Revista de las Cortes Generales, núm. 109, 2020, pp. 187-208; F. J. Carrera HernándeZ, «Del Mecanismo Europeo de Estabilidad 
mente largo y tenso Consejo Europeo de julio de $2020^{7}$ — si bien la negociación de los reglamentos llevaría unos seis meses más-.

El 27 de mayo, la presidenta de la Comisión Europea, Úrsula von der Leyen, propuso la creación de un nuevo plan de recuperación de la UE (Next Generation EU) por 750.000 millones de euros (a precios de 2018) a gastar en 2021-2026 para impulsar el presupuesto de la UE con nueva financiación obtenida de los mercados financieros ${ }^{8}$. No se debe olvidar que en febrero la posición del Consejo Europeo de los Estados miembros contribuyentes netos era reducir el presupuesto tradicional de la UE 2021-2027 (1.100.000 millones de euros lo más cerca posible al 1 por 100 de la RNB de la UE) ${ }^{9}$.

De acuerdo con las propuestas más idealistas de España y aceptada por el eje francoalemán, los fondos recaudados en los mercados financieros serían luego canalizados por los programas europeos existentes (esto también permitirá su escrutinio por parte de los eurodiputados) ${ }^{10}$. Contrariamente a las demandas de los países denominados «frugales», aquellos Estados miembros que son contribuyentes netos al presupuesto plurianual de la UE, la Comisión ha recurrido anteriormente a la ingeniería financiera, aunque la escala del endeudamiento del NGEU no tiene precedente. ${ }^{11}$.

Si bien se había propuesto que la mayor parte ( 500.000 millones) se otorgase en forma de subvenciones, al final serán 312.500 millones, dada la presión de los contribuyentes netos a que la mayoría de los fondos fuesen disponibilizados como créditos del 4,2 por 100 de la Renta Nacional Bruta, lo que a su juicio reduciría la propensión al gasto irresponsable (y de paso la factura para los contribuyentes netos, dado que a no ser que se establezcan los llamados recursos propios, o impuesto europeos ${ }^{12}$, a ellos les correspondería hacer frente a los créditos del NGEU). Esta deuda de la UE debería reembolsarse después de 2027, y a más tardar en 2058, para que los Estados miembros no tengan que hacer contribuciones adicionales significativas al presupuesto de la UE para el periodo 2021-2027. Next Generation EU es un título apropiado, dado que se reembolsará durante al menos una generación.

(MEDE) al nuevo Mecanismo de Recuperación y Resiliencia (MRR): ¿Ha sido necesaria una pandemia para reforzar la solidaridad financiera en la Unión Europea?», Revista Española de Derecho Europeo, núm. 75, 2020, pp. 9-53.

7 Consejo Europeo, Special meeting of the European Council (17, 18, 19, 20 and 21 July 2020) - Conclusions, EUCO 10/20.

8 Reglamento (UE) 2020/2094 del Consejo de 14 de diciembre de 2020 por el que se establece un Instrumento de Recuperación de la Unión Europea para apoyar la recuperación tras la crisis de la covid-19.

9 S. Pazos-Vidal, «Presupuesto Europeo, Regiones y Agricultura», Agenda Pública, 27 de febrero de 2020, http:/lagendapublica.elpais.com/presupuesto-europeo-regiones-y-agricultural.

${ }_{10}$ Gobierno alemán, Overcoming the crisis united and emerging from it stronger, 18 de mayo de 2020. Gobierno de España, Spain's Non-Paper on a European Recovery Strategy, 19 de abril de 2020.

11 M. Otero Iglesias, "Europe’s Coronavirus Identity Crisis», Politico, 1 de abril de 2020, https://www. politico.eularticleleuropes-coronavirus-pandemic-economic-identity-crisis-corona-bonds/.

12 Impuestos de la UE sobre cuestiones como las emisiones (según se informa, 10.000 millones por año), las exportaciones de carbono (5.000 millones), grandes empresas (también 10.000 millones), digitales (1.300 millones). Vid. A. D'Alfonso, National ratification of the Own Resources Decision State of play on 18 March 2021, European Parliament Members' Research Service, 2021, PE 690.520. 
La mayor parte de la Next Generation EU está formada por el nuevo Mecanismo de Recuperación y Resiliencia ${ }^{13}$. Con un presupuesto de no menos de 672.000 millones, sería tan grande (si contamos los 360.000 millones en préstamos) como el gasto de la Política de Cohesión de la UE y la PAC combinadas - y que signe suponiendo dos tercios del presupuesto ordinario de la UE-, el MRR es el mayor programa presupuestario de la UE jamás creado ${ }^{14}$.

Parecería lógico que el coloquialmente llamado Mecanismo de Recuperación contase con un solo instrumento, el MRR. Pero en la génesis del conjunto de varios fondos y créditos que es el NGEU interviene no solo el aspecto temporal, como el de las inercias institucionales.

Inicialmente la Comisión Europea, estimando que la crisis sería menos grave, propuso simplemente agilizar el gasto de los Fondos Estructurales 2014-2020 (que ya iban muy retrasados) mediante la Iniciativa de inversión en respuesta al coronavirus - Coronavirus Response Investment Initiative y Coronavirus Response Investment Initiative Plus - que fundamentalmente prevén una reprogramación de los fondos ya asignados 2014-2020 para costes elegibles derivados de la pandemia, con una cofinanciación al 100 por $100^{15}$.

Por la propia dinámica incremental de las decisiones europeas, y la necesidad de atender a equilibrios internos dentro de la Comisión (y sus apoyos externos, incluidos ministerios de cada ramo), al MRR se le sumó dentro del Next Generation EU con un nuevo Fondo Estructural, el REACT EU, 47.500 millones de euros (a comprometer en 2021-2022), para atender las necesidades económicas y sociales más urgentes como resultado de las consecuencias económicas en curso. En la práctica se gestiona como un Fondo Estructural clásico, aunque se financie como deuda y no mediante el presupuesto ordinario.

El NGEU también aporta financiación adicional mediante el recurso a la deuda para otros fondos del presupuesto tradicional, 7.500 millones de euros para el Fondo Europeo Agrícola de Desarrollo Rural (FEADER) y otros tantos el nuevo instrumento del Fondo de Transición Justa (que es en la práctica un pequeño fondo estructural para provincias o similares —el nivel NUTS3 de la clasificación Eurostat- afectadas por reconversión energética ${ }^{16}$.

13 Reglamento (UE) 2021/241, del Parlamento Europeo y del Consejo, de 12 de febrero, por el que se establece el Mecanismo de Recuperación y Resiliencia.

14 Para un análisis pormenorizado vid. E. FEÁs, «Las cifras del Plan de Recuperación para Europa», Análisis del Real Instituto Elcano (ARI), núm. 86, 2020.

15 Reglamento (UE) 2020/460, del Parlamento Europeo y del Consejo, de 30 de marzo, por el que se modifican los Reglamentos (UE) núm. 1301/2013 (UE) núm. 1303/2013 y (UE) núm. 508/2014, en lo relativo a medidas específicas para movilizar inversiones en los sistemas de atención sanitaria de los Estados miembros y en otros sectores de sus economías, en respuesta al brote de covid-19 (iniciativa de inversión en respuesta al coronavirus).

16 CONSEJO DE LA UE, Just Transition Fund (JTF) Regulation - Confirmation of the final compromise text with a view to agreement, 6183/21, Brussels, 25 de febrero de 2021; S. PAZOS VIDAL, «Transición Justa y Fondos Europeos", Agenda Publica, 15 de enero de 2020, https://agendapublica.es/transicion-justa-y-fondos-europeos/. 


\section{LAS REFORMAS ESTRUCTURALES Y LA POLÍTICA DE COHESIÓN}

El Mecanismo de Recuperación y Resiliencia no nació al calor de la covid-19. La crisis de la pandemia permitió la expansión exponencial (treinta veces) de un Programa de Reformas Estructurales preexistente que preveía 25.000 millones para 2021-2027. Este fondo destinado a afrontar los males endémicos de incumplimiento de las reformas estructurales de tipo macroeconómico y de falta de capacidad institucional y modernización administrativa que cada Estado miembro acordaba en su Plan Nacional de Reforma con la Comisión en el proceso del llamado Semestre Europeo para luego incumplir, por falta de incentivos coercitivos o de recursos para hacerlo ${ }^{17}$.

De hecho el surgimiento del MRR tiene más que ver con el uso de la crisis de la covid-19 para imponer de las tesis que defendían, desde el Secretariado General de la Comisión y otros, la necesidad de un fondo específico para asegurar el cumplimento de las reformas estructurales acordadas en el Semestre Europeo, estimando que los instrumentos existentes de la política de cohesión son demasiado ineficientes en parte, dado su carácter territorial y multinivel ${ }^{18}$.

La Política de Cohesion había intentado responder a estas demandas ${ }^{19}$ particularmente, empezando por una mayor vinculación de los Fondos Estructurales al cumplimiento de condiciones ex ante y macroeconómicas vinculadas al Semestre ${ }^{20} \mathrm{y}$, al partir del Sexto Informe de la Cohesión (2014) ${ }^{21}$ por un mayor enfoque en la calidad del buen gobierno como principal barrera para la que los FEIE obtuviesen cambios estructurales,

17 J. Zeitlin y B. VAnHercke, «Socializing the European Semester: EU social and economic policy coordination in crisis and beyond", Journal of European Public Policy, vol. 25, núm. 2, 2018, pp. 149-174.

S. PAZOS-VIDAL, «Rethinking governance after the covid-19 crisis: challenges and opportunities for power devolution and self-government», Rethinking governance after the covid-19 crisis - Post-Covid Europe Coppieters Foundation, 2021.

${ }_{18}$ La política de cohesión de la UE, que tiene sus orígenes en la tradición de la Administración pública francesa en lo que respecta a la cultura organizativa, la gestión presupuestaria y financiera y los procedimientos de auditoría, impone una responsabilidad importante a la hora de garantizar la legalidad y regularidad de sus gastos. Vid. A. FALUDI, «A historical institutionalist account of European spatial planning», Planning Perspectives, vol. 3, núm. 4, 2018, pp. 507-522.

19 Podemos citar, entre otras iniciativas de la DG REGIO de la Comisión Task Force for Better Implementation (2014), para los países más retrasados en la absorción de fondos, los Pactos de Integridad entre la DG REGIO, Transparencia Internacional Pactos de Integridad (2015), la Iniciativa de Regiones Rezagadas (2015, 2017), las Comunidades de Practicantes TAIEX-REGIO PEER 2 PEER, REGIO y, de hecho, la creación de la Unidad de Capacidad Administrativa de la DG REGIO. También la Iniciativa de desarrollo de la capacidad administrativa para después de 2020 (Grecia, Polonia, España, Croacia y Bulgaria). T. FArole, S. Goga y M. IOnescu-Heroiu, Rethinking Lagging Regions: Using Cohesion Policy to Deliver on the Potential of Europes Regions. World Bank, Washington, 2018.

20 R. HALL, «The Development of Regional Policy in the Process of European Integration: An Overview», en G. BisChOF (ed.), Regional Economic Development Compared: EU-Europe and the American South, Innsbruck University Press, Innsbruck, 2015, pp. 13-33.

21 COMISIÓN Europea, Investment for jobs and growth. Promoting development and good governance in EU regions and cities: sixth report on economic, social and territorial cohesion, 2014, p. 235: id., My Region, My Europe, Our Future - Seventh report on Economic, Social and Territorial Cohesion, 2017, pp. XXI, 135-161. 
incluido como uno de 11 Objetivos Temáticos comunes a todos los fondos EIE en el periodo 2014-202022.

A pesar de estos, desde la Dirección General de Política Regional y Urbana (DG REGIO), la Comisión Juncker, consciente de la capacidad limitada de la mayoría de los Estados miembros, e incluso de la Comisión, para convertir en realidad las reformas acordadas en el semestre ${ }^{23}$, comenzó a centrar su atención en los incentivos para la «reforma estructural».

En 2014 se creó un Servicio de Apoyo a la Reforma Estructural para respaldar las reformas de los Estados miembros en áreas de competencia nacional y no compartida. De ahí se pasó a un Programa de Apoyo a las Reformas Estructurales (SRSP) 2017-2020 por un valor inicial de 142,8 millones de euros. Y el llamado paquete de Unión Económica y Monetaria de diciembre de 2017 amplió su presupuesto a 300 millones de euros, pero con la opción — para sorpresa de DG REGIO_ de poder destinar el 6 por 100 de los Fondos Estructurales 2014-2020 24 .

La génesis de este nuevo fondo de reformas estructurales se completó solo cinco meses después, cuando en mayo de 2018 la propuesta de presupuesto de la UE para 2021-2027 de la Comisión incluyó un nuevo programa de apoyo a la reforma (SRP) con un presupuesto no inferior a 25.000 millones de euros (con una opción de transferencia de un 5 por 100 adicional desde los Fondos EIE 2021-2027) ${ }^{25}$. Este fondo no vio la luz porque en $2020 \mathrm{y}$ al calor de la covid-19 fue sustituido por el MRR, con un presupuesto treinta veces superior ${ }^{26}$.

No hay duda del éxito del programa SRR con 669 actividades financiadas, incluido a nivel municipal, hasta el comienzo de la pandemia. Pero estas también confirman la enorme amplitud del concepto «reforma» en las instituciones europeas. Definir conceptos, y más que sean jurídicamente operativos como «reformas» o «capacidad administrativa», sigue siendo esquivo ${ }^{27}$. RODRÍGUEZ-POSE y GARCILAZO llegan a decir que: «Por

224.300 millones de euros de Fondos Estructurales de la UE dedicados a ella, un aumento del 72 por 100 en comparación con el último periodo. Cfr. COMISIÓn EuropeA, ibid., 2014, pp. iii, xviii, xxxii.

${ }^{23}$ K. Featherstone, "Conditionality, Democracy and Institutional Weakness: the Euro-crisis Trilemma», Journal of Common Market Studies, vol. 54, núm. 9, 2016, pp. 48-64.

${ }_{24}$ S. PAZOS-Vidal, Subsidiarity and EU Multilevel Governance. Actors, Networks and Agendas, Routledge, Abingdon, 2019.

25 COMISIÓN EUROPEA, «Un presupuesto moderno para una Unión que protege, empodera y defiende: el marco financiero plurianual para 2021-20», SWD (2018) 171, p. 34; id., "Un presupuesto moderno para una Unión que protege, empodera y defiende: el marco financiero plurianual para 2021-2027», Comunicación. COM (2018) 321 final.

26 Comisión Europea, Propuesta de Reglamento por el que se modifica el Reglamento (UE) núm. 1.303/2013, COM/2017/0826 final.

27 La definición de la OCDE es «capacidad para desempeñar funciones, resolver problemas, establecer y alcanzar objetivos», vid. S. Willems y K. BAUMerT, Institutional Capacity and Climate Actions, OCDE, 2007; H. ADDISON, «Is Administrative Capacity a Useful Concept? Review of the Application, Meaning and Observation of Administrative Capacity in Political Science Literature», LSE Research Paper, 2009. http://personal.lse. ac.ukladdisonh/Papers/AC_Concept.pdf. 
encima de un umbral de gasto de cohesión — calculado en más de 120 euros de gasto de cohesión per cápita por año- las mejoras de la calidad del gobierno son una opción mucho más importante y realista para el desarrollo regional que la inversión pública adicional ${ }^{28}$. De ser cierta su hipótesis, esta inyección de dinero adicional del MRR, a mayores del MFP clásico, sin que se priorice la capacidad administrativa y las reformas, podría ser incluso contraproducente.

\section{EL MECANISMO DE RECUPERACIÓN Y RESILIENCIA}

El Reglamento (UE) 2021/241, del Parlamento Europeo y del Consejo, de 12 de febrero, por el que se establece el Mecanismo de Recuperación y Resiliencia (MRR), va a financiar el mayor paquete de inversiones de la historia de la UE. Sin embargo, en comparación con lo mucho más detallados Reglamento de Disposiciones Comunes (RDC) de los Fondos Estructurales ${ }^{29}$ y los reglamentos que rigen cada fondo, es un Reglamento muy corto (36 artículos) y muy general con definiciones y disposiciones reglamentarias sujetas a amplias interpretaciones durante su ejecución.

Se confirma que la base legal en los Tratados es el art. 174 del Tratado sobre el Funcionamiento de la Unión Europea (TFUE). Es precisamente la misma que la de Fondos Estructurales tradicionales: la UE tiene como objetivo la «cohesión económica, social y territorial de la UE», reduciendo «las diferencias entre los niveles de desarrollo de las diversas regiones y el retraso de las regiones menos favorecidas» y aunándolo con el art. 175 TFUE que establece, entre otras cosas, que los Estados miembros deben coordinar sus políticas económicas con miras a alcanzar los objetivos de cohesión económica, social y territorial enunciados en el art. 174 TFUE (cdo. 2 MRR).

Los ejes prioritarios (art. 3 MRR) del ámbito de aplicación del MRR son seis y, como veremos, muy coincidentes con los nuevos 5 Objetivos Políticos de la Politica de Cohesión para 2021-2027 (en el periodo anterior eran 11): a) transición ecológica; b) transformación digital; c) crecimiento inteligente, sostenible e integrador, que incluya la cohesión económica, el empleo, la productividad, la competitividad, la investigación, el desarrollo y la innovación, y un mercado interior que funcione correctamente con pymes sólidas; d) cohesión social y territorial; e) salud y resiliencia económica, social e ins-

28 A. Rodríguez-Pose y E. Garcilazo, «Quality of Government and the Returns of Investment: Examining the Impact of Cohesion Expenditure in European Regions», Regional Studies, vol. 49, núm. 8, 2015, pp. 1274-1290 (esp. p. 1274).

29 El texto definitivo ha sido acordado en diciembre, y si bien la ratificación del mismo por el Consejo y el Parlamento es una formalidad, nos referiremos en el texto del acuerdo (en su original en inglés, las traducciones son en español) que figura en el Registro del Consejo. Vid. Secretaría General del Consejo, Common Provisions Regulation - Analysis of the final compromise text with a view to agreement, $\operatorname{COM}(2018)$ 375 final, Brussels, 25 de febrero de 2021, 6180/21, https://data.consilium.europa.euldoc/document/ST-61802021-INIT/en/pdf. 
titucional, con objeto, entre otros, de aumentar la preparación y capacidad de reacción ante las crisis, y $f$ ) políticas para la próxima generación, la infancia y la juventud, tales como la educación y el desarrollo de capacidades.

Como veremos en el caso concreto de España, existe un gran solapamiento con las cinco grandes prioridades de Política de Cohesión, exigiendo, eso sí, que se concentrase el 37 por 100 del MRR en el objetivo climático y el 20 por 100 en el digital, una concentración temática no muy diferente a la de los Fondos Estructurales (vid. infra). Son objetivos muy generales, y salvo en el caso del eje climático y digital (que tiene unos indicadores muy precisos en los Anexos VI y VII respectivamente), el Reglamento es bastante genérico respecto al tipo de inversiones deseadas. Si bien es cierto que en septiembre de 2020 la Estrategia Anual de Crecimiento Sostenible $2021^{30}$ siete «iniciativas emblemáticas europeas", como, por ejemplo, doblar en toda la UE el porcentaje de edificios a los que se le ha mejorado la eficacia energética, estas iniciativas no se vinculan ${ }^{31}$ explícitamente con el MRR, por lo se queda en un criterio de evaluación de la Comisión más que una imposición ex ante a los Estados miembros.

El art. 2.4 MRR define como criterio de ejecución fundamental del MRR los «hitos y objetivos»: las medidas de progresión hacia la consecución de una reforma o una inversión, considerándose que los hitos constituyen logros cualitativos y los objetivos constituyen logros cuantitativos; y cuyo cumplimiento es preceptivo para que la Comisión, que según el art. 8 ejecuta el MRR en régimen de gestión directa ${ }^{32}$, efectúe a los Estados miembros el reembolso (al 100 por 100) de los proyectos, o partes del mismo (es decir, los hitos) ya ejecutados.

De los hitos y metas se dice que sean "claros y realistas, y los indicadores propuestos deben ser relevantes, aceptables y sólidos. Pueden reflejar diferentes etapas de la implementación de reformas e inversiones, ya sea en base a indicadores de insumos (p. ej., recursos proporcionados, que pueden ser financieros, humanos, administrativos) o preferiblemente indicadores de resultados (p. ej., número de trabajadores capacitados, número de escuelas renovadas)» ${ }^{33}$.

La guía que acompaña al Reglamento aclara que «un objetivo es un logro cuantitativo en un indicador acordado (número de kilómetros de vías férreas construidas, número de metros cuadrados de edificio renovado, número de beneficiarios de un plan de inversión particular, etc.). La elección de los objetivos debe reflejar la implementación de reformas y inversiones y, por tanto, estar operativo. Un hito no refleja cantidades, sino

30 Comunicación de la Comisión, «Estrategia anual de crecimiento sostenible 2021», COM(2020) 575 final, 17 de septiembre de 2020.

31 La Estrategia Europa 2020 también creó en 2010 unas iniciativas "Flagship» similares que se quedaron en el papel.

32 De conformidad con las normas pertinentes adoptadas en virtud del art. 322 TFUE, en particular el Reglamento Financiero y el Reglamento (UE, Euratom) 2020/2092, del Parlamento Europeo y del Consejo.

33 Comisión EuropeA, «Commission Staff Working Document Guidance to Member States Recovery and Resilience Plans», SWD(2021) 12 final Part 1/2, Brussels, 22 de enero de 2021, p. 33. 
más bien un logro cualitativo objetivamente verificable (legislación adoptada, plena operatividad de los sistemas de TI, etc.) y detalla el contenido y las características deseables. Una línea de base refleja el estado, cuantitativo o cualitativo, de la variable/indicador según el cual se mide, excluyendo la intervención de política» ${ }^{34}$.

Se traslada, pues, una metodología la del pago en función a hitos superados que viene del Banco Mundial, pero que en intentos anteriores en la UE (p. ej., los llamados Joint Action Plans ${ }^{35}$ fracasaron estrepitosamente, ya que ninguna administración quiso usar esa metodología por el riesgo potencial de auditoría, al ser tan diferente a la forma en la que se gestionan los fondos de la UE.

Las inversiones pueden ser directas (p. ej., financiar un proyecto con dinero público) o indirectas (p. ej., programas públicos para incentivar inversiones privadas, como, p. ej., renovaciones de edificios para mejorar la eficiencia energética y de recursos o la digitalización de pequeñas empresas) ${ }^{36}$.

La diferencia del MRR, como fondo de gestión directa por la Comisión, con los fondos de gestión compartida - fundamentalmente los Fondos Estructurales- con los Estados miembros, en la práctica no lo es tanto, con el MRR se abarcan toda una serie de proyectos muy localizados sobre los que la Comisión no va a tener un rol directo como tal (como sí ocurría en las antiguas iniciativas innovadoras en la Política de Cohesión — la iniciativa URBAN de regeneración urbana-, o en los programas transnacionales de gestión directa como el programa de investigación Horizon Europe $)^{37}$, sino que va a evaluar su cumplimiento y autorizar el reembolso (al 100 por 100, no como con los Fondos Estructurales) evaluando la ejecución anual del conjunto del Plan de Recuperación, o como mucho, de cada uno de sus grandes ejes, en términos de su impacto en las grandes cifras macroeconómicas y sociales — por eso el pago por hitos- en función del cumplimiento de hitos previamente establecidos hasta el mes de agosto de 2026, si bien los proyectos podrán seguir ejecutándose hasta final de año ${ }^{38}$.

Por tanto, lo fundamental del diseño, gestión y evaluación del MRR será a nivel doméstico; la Comisión se reserva en la práctica el rol de evaluador y pagador, como con los Fondos Estructurales. Tendrá que fiarse de la buena gestión de los Estados miembros y la información que estos transmitan para ir autorizando los reembolsos.

34 Ibid., p. 34.

35 Comisión EuropeA, "Guidance on Joint Action Plans Structural and Cohesion Funds 2014-20 Version of June 2015», 2015.

36 Comisión Europea, "Commission Staff Working Document Guidance to Member States Recovery and Resilience Plans», SWD(2021) 12 final Part 1/2, Brussels, 22 de enero de 2021, p. 15.

37 La DG REFORM responsable del MRR, cuenta con menos de 200 funcionarios. Y de hecho, la Comisión no está dispuesta a volver a la época en la que centralizaba la gestión de programas pequeños en Bruselas. Vid. J. BACHTLER y C. MÉNDEZ, "Who governs EU cohesion policy? Deconstructing the reforms of the structural funds», Journal of Common Market Studies, vol. 45, núm. 3, 2007, pp. 535-564.

38 Comisión EuropeA, "Commission Staff Working Document Guidance to Member States Recovery and Resilience Plans», SWD(2021) 12 final Part 1/2, Brussels, 22 de enero de 2021, p. 48. 
Es por tanto una escala temporal aún más ajustada que con los Fondos Estructurales ya que es necesario comprometer todos los fondos en 2021-2023 (y no a siete años), y a gastar en seis, es un año menos que en el MFP. Tampoco prevé una regla N+3 que sí permite en los Fondos Estructurales gastar los fondos tres años tras haber sido comprometidos, sino que los pagos (o en su caso, préstamos al Estado miembro) se efectuarán el 31 de diciembre de 2026 a más tardar (art. 24.1 MRR). Sin embargo, cuando los Estados miembros no hayan realizado «avances tangibles» tras dieciocho meses (es decir, año y medio) en el Plan de Recuperación la Comisión liberará (es decir, dejará de reembolsar) el importe de la contribución financiera prevista para ese Estado miembro (art. 20.1 MRR).

Al igual que los Fondos FEIE, y dada la breve escala temporal, se dotará de una prefinanciación más generosa de lo inicialmente propuesto por la Comisión: un 13 por 100 del total previsto para 2021-2022 (art. 13 MRR). En todo caso, estamos hablando de un fondo que difícilmente se puede considerar de shock anticrisis, ya que en 2021 se disponibilizará fundamentalmente la prefinanciación y el resto de las asignaciones del $\mathrm{MRR}^{39}$ se liberarán según se vayan cumpliendo hitos a lo largo de seis años.

Los Planes de Recuperación y Resiliencia (art. 18) serán coherentes con los retos y prioridades específicos de cada país, determinados en el marco del Semestre Europeo (art. 17.3.). Dichos planes, conocido en España como «Plan España Puede», debe explicar cómo sus actuaciones se relacionan con los compromisos adquiridos por el Estado miembro en el marco del Semestre Europeo a partir de las Recomendaciones Específicas por país que la Comisión efectúa cada año en virtud del art. 6 del Reglamento (UE) núm. 1176/2011, de 16 de noviembre [art. 18.4.b) MRR] ${ }^{40}$. También deben aportar una explicación cualitativa de cómo se espera que las medidas del plan de recuperación y resiliencia contribuyan a la transición ecológica, incluida la biodiversidad, o a hacer frente a los retos derivados de ellas, y de si representan un importe equivalente a como mínimo el 37 por 100 de la dotación total del plan de recuperación y resiliencia [art. 18.4.e) MRR], una explicación de cómo se espera que las medidas del plan de recuperación y resiliencia contribuyan a la transición digital o a los retos que se derivan de esta, y si representan un importe equivalente a como mínimo el 20 por 100 de la dotación total del Plan de Recuperación y Resiliencia [art. 18.4.f) MRR], los hitos y objetivos previstos, así como un calendario indicativo para la realización de las reformas e inversiones con plazo de finalización hasta el 31 de agosto de 2026 [art. 18.4.i) MRR], los proyectos de inversión previstos y su periodo de inversión [art. 18.4.j) MRR] y una estimación del coste total de ras reformas [art. 18.4.k) MRR]. La Comisión tendrá dos meses para

39 Basada en los dos tercios de los fondos asignados a cada Estado, y no del total estimado, ya que el último 30 por 100 solo se asignará entre el 1 de enero de 2023 y el 31 de diciembre de 2023 en base a una metodología que sí tendrá en cuenta el impacto real de la covid-19 (art. 12 MRR).

40 Para un análisis reciente sobre el Semestre en España, vid. P. García Perea, A. Millaruelo, V. M. Mora BAjÉn y C. SÁNCHEZ CARRETERO, «El semestre europeo 2020 y las recomendaciones específicas para España», Boletín económico - Banco de España, núm. 3, 2020, pp. 129-147. 
evaluar dichos planes, que se deberán enviar a más tardar el 30 de abril (art. 18.3 MRR), o sus modificaciones (art. $19 \mathrm{MRR}$ ), tras lo cual se iniciaría el proceso de liberación de fondos mediante propuesta de decisión de ejecución del Consejo de conformidad con el art. 20, apartado 1 (MRR) ${ }^{41}$.

Por tanto, grosso modo, el contenido de Plan de Recuperación y Resiliencia es bastante semejante al (aunque separado del) Acuerdo de Asociación (Título II, Capítulo I RDC) que rige los Fondos Estructurales en cada Estado miembro.

Del mismo modo, y al igual que en el caso de los Fondos Estructurales (Título II, Capítulo III RDC), se crea un cuadro de indicadores de la recuperación y la resiliencia (art. $30 \mathrm{MRR}$, que mostrará los avances en la aplicación de los planes de recuperación y resiliencia de los Estados miembros en cada uno de los seis pilares de actuación prioritaria del MRR mencionados en el art. 3 MRR y que constituirá el sistema de información sobre el rendimiento del Mecanismo los indicadores comunes previstos en el art. 29.4 MRR. El Anexo V contiene unas Directrices de evaluación del Mecanismo bastante generales con los que la Comisión evaluará los planes presentados. Si bien el Anexo VI contiene una Metodología de seguimiento para la acción por el clima bastante detallada - habida cuenta que es una prioridad del MRR - y el Anexo VII una Metodología para el etiquetado digital en el marco del Mecanismo (es decir, de las intervenciones del MRR en materia de digitalización), diferencia del Marco de Rendimiento de los Fondos Estructurales 2014-2020 en el que todo el marco de rendimiento estaba definido ex ante en el propio Reglamento CPR 2014-2020, para el conjunto de intervenciones del MRR se diseñará ex post en función de los planes enviados y será operativo a más tardar en diciembre de 2021 y será actualizado por la Comisión dos veces al año (art. 30.4 MRR). Esto obviamente refleja la naturaleza improvisada de la génesis de este Reglamento, y la ya citada naturaleza cualitativa y continente, por no decir concepto jurídicamente indeterminado, del concepto de «reformas». De hecho, la definición más concisa de «reforma» no se encuentra en el articulado del Reglamento del MRR, sino la guía — sin valor jurídico- que lo acompaña (op. cit., p. 14): «Una reforma es una acción o proceso de realizar cambios y mejoras con un impacto significativo y efectos duraderos en el funcionamiento de un mercado o política, el funcionamiento o estructuras de una institución o administración, o en el progreso hacia los objetivos políticos relevantes. Como el crecimiento y el empleo, la resiliencia y las transiciones gemelas. Se deben considerar todos los tipos de reformas en el marco del Mecanismo, incluidas aquellas que no requieren ningún financiamiento específico».

Dada la amplitud de los conceptos clave sobre los que se basa el MRR es obvio que las medidas contra la corrupción (art. $18 \mathrm{MRR}$ ) son tan importantes — como había alertado el Dictamen del Tribunal de Cuentas Europeo-, que también estima que

41 El controvertido rol del Consejo (una demanda de los contribuyentes netos que temían una Comisión demasiado tolerante con Planes nacionales poco robustos) es una gran diferencia con los Fondos Estructurales ya que el Consejo (es decir, el resto de Estados miembros) que no interviene. Una vez más, la distinción entre fondos de gestión directa y compartida es en la práctica más sutil de lo que parece. 
existe descompensación entre la escala temporal de los hitos y de los pagos, entre las necesidades de los Estados y la fórmula de reparto y, aspecto clave, entre el carácter general de las Recomendaciones Especificas por país que la Comisión efectúa en el marco del Semestre Europeo y su concreción en Programas Nacionales de Reforma, así como posteriormente su traslación a las prioridades de inversión del MRR, por no hablar por el gran solapamiento con los Fondos Estructurales ${ }^{42}$.

En ese sentido, el art. $28 \mathrm{MRR}$ establece las medidas de coordinación, complementariedad, sinergia, coherencia con los otros fondos, nacionales y europeos, y sobre todo con los Fondos Estructurales. Ahora bien, en absoluto estamos hablando de una demarcación ex ante y precisa entre los fondos, como si ocurría en el periodo 2014-2020 entre los Fondos Estructurales, incluido el FEADER, mediante el Marco Estratégico Común (Anexo I RDC 2014-2020) ${ }^{43}$. Esa demarcación desaparece de todos modos para los Fondos Estructurales (con el FEADER enteramente de nuevo fuera del nuevo Reglamento de Disposiciones Comunes 2021-2027 e integrado en su lugar en los Planes Estratégicos de la PAC de cada Estado miembro, que es el nuevo equivalente agrícola y rural de los Acuerdos de Asociación para los Fondos FEIE restantes) ${ }^{44}$. El MRR reproduce esa tenue demarcación entre los diferentes fondos «estructurales», lato sensu, lo que sin duda arriesga a inversiones cruzadas, duplicidades y huecos entre los diversos fondos de recuperación, estructurales y agrícolas.

Por lo que se refiere a la participación de las administraciones y gobiernos territoriales, el art. 18.q) MRR se refiere al "mecanismo de consulta» para la preparación, y a la aplicación del Plan de Recuperación y Resiliencia de las «autoridades locales y regionales, los interlocutores sociales, las organizaciones de la sociedad civil, las organizaciones juveniles y otras partes interesadas pertinentes, y cómo se reflejan en ese plan las aportaciones de las partes interesadas».

En este sentido, el considerando $34 \mathrm{RR}$ reconoce que «las autoridades regionales y locales» pueden ser socios importantes en la aplicación de las reformas y las inversiones.

42 Tribunal de Cuentas Europeo, Dictamen núm. 6/2020 [con arreglo a los arts. 287, apdo. 4, y 322, apdo. 1, letra a), del TFUE] sobre la propuesta de Reglamento del Parlamento Europeo y del Consejo por el que se establece un Mecanismo de Recuperación y Resiliencia [COM(2020) 408] (2020/C 350/01), 20 de octubre de 2020, ES Diario Oficial de la Unión Europea, C 350/1.

43 Reglamento (UE) núm. 1303/2013, del Parlamento Europeo y del Consejo, de 17 de diciembre, por el que se establecen disposiciones comunes relativas al Fondo Europeo de Desarrollo Regional, al Fondo Social Europeo, al Fondo de Cohesión, al Fondo Europeo Agrícola de Desarrollo Rural y al Fondo Europeo Marítimo y de la Pesca, y por el que se establecen disposiciones generales relativas al Fondo Europeo de Desarrollo Regional, al Fondo Social Europeo, al Fondo de Cohesión y al Fondo Europeo Marítimo y de la Pesca, y se deroga el Reglamento (CE) núm. 1083/2006, del Consejo.

44 Propuesta de Reglamento del Parlamento Europeo y del Consejo por el que se establecen normas en relación con la ayuda a los planes estratégicos que deben elaborar los Estados miembros en el marco de la política agrícola común (planes estratégicos de la PAC), financiada con cargo al Fondo Europeo Agrícola de Garantía (FEAGA) y al Fondo Europeo Agrícola de Desarrollo Rural (Feader), y por el que se derogan el Reglamento (UE) núm. 1305/2013, del Parlamento Europeo y del Consejo, y el Reglamento (UE) núm. 1307/2013, del Parlamento Europeo y del Consejo. 
A este respecto, se les debe hacer partícipes y consultar debidamente, de conformidad con el marco jurídico nacional». Si bien su cooperación es necesaria en la ejecución de los fondos [art. 28.c) MRR], lo cierto es que el mecanismo de consulta del MRR dista mucho del llamado principio de Asociación o «Partenariado», al menos formalmente, ya que el principio de asociación (art. $6 \mathrm{RDC}$ ) supone, como confirma el considerando 11 $\mathrm{RDC}$ es una característica clave en la ejecución de los Fondos, basándose en el enfoque de gobernanza multinivel y asegurando la participación —es decir, no solo la mera consulta-, en todas las fases de diseño, gestión y evaluación de los Fondos FEIE por las autoridades públicas regionales, locales, urbanas y de otro tipo, la sociedad civil, los interlocutores económicos y sociales y, cuando proceda, instituciones de investigación y universidades.

Sobre todo, y esta es la novedad del periodo 2014-2020, este principio consustancia la política de Cohesión que tiene desde entonces y también para 2021-2020, un desarrollo normativo que especifica cómo debe de funcionar el partenariado: el Reglamento Delegado (UE) núm. 240/2014, de 7 de enero, relativo al Código de Conducta Europeo sobre las asociaciones en el marco de los Fondos Estructurales y de Inversión Europeos.

Si bien en la práctica este partenariado en los Fondos FEIE es más teórica que real ${ }^{45}$ sobre todo por la amplia discrecionalidad que tienen los Estados para involucrar a autoridades locales y regionales competentes y actores de la sociedad civil, para el MRR no se ha querido introducir el principio de asociación, pese a la oposición del Parlamento y el Comité de las Regiones ${ }^{46}$. Por tanto, no sorprende las primeras evidencias ya evidencias apuntan a una débil involucración de los niveles subestatales en el diseño de los planes nacionales de recuperación — como veremos en el caso español infra— ${ }^{47}$.

En conclusión, el MRR es en lo fundamental un nuevo fondo estructural, tan grande como los Fondos FEIE y la PAC juntos: tiene la misma base legal, un diseño y ejecución bastante semejantes (planes nacionales y un cuadro de rendimiento, pago por la Comisión a gasto efectuado), pero se diferencia en aspectos clave como es la ausencia de cofinanciación en el MRR (es decir, la UE reembolsa al 100 por 100) y en la gobernanza territorial. Cierto es que el MRR no impide que los Estados miembros

45 S. PAZOS-VIDAL, Partnership Agreements CEMR Survey Report on "Involvement of national associations of LRAs in the Partnership Agreement preparations" Council of European Municipalities and Regions, 2013; id., "The Partnership Principle in Cohesion Policy 2014-2020 Breaking New Ground in Multi-Level Governance?», European Structural and Investment Funds Journal, vol. 2, núm. 4, 2014, pp. 277-288.

46 Informe del Parlamento Europeo sobre la propuesta de Reglamento del Parlamento Europeo y del Consejo por el que se establece un Mecanismo de Recuperación y Resiliencia [COM(2020)0408 - C9-0150/2020 - 2020/0104(COD)], 10 de noviembre de 2020.

${ }_{47}$ Como se evidencia en este estudio - por transparencia: el autor ha sido partícipe indirecto de su elaboración - ni en Estados de gran tradición consociativo como Países Bajos ni siquiera federales como Alemania, el rol de los niveles subestatales en la preparación de los planes MRR ha sido relevante, en contraste con lo que pasa en esos mismos países con la formulación, preparación y ejecución de los Fondos Estructurales. Vid. Comité de las Regiones - Consejo de Municipios y Regiones de Europa, «La participación de municipios, ciudades y regiones en la preparación de los planes nacionales de recuperación y resiliencia: resultados de la consulta específica del CDR-CMRE», 2021. 
reproduzcan el principio de Asociación y la arquitectura subnacional de los fondos FEIE en base a Programas Operativos y la gestión delegada de los mismos por las administraciones territoriales, pero tampoco los anima. El MRR presupone de grandes proyectos que actúen de choque a la crisis económica y social poscovid que mejoren los indicadores macro ${ }^{48}$.

Last but not least, el art. 7 MRR permite la transferencia ilimitada de fondos de gestión compartida (fundamentalmente los Fondos Estructurales) para ser gastados a través del MRR, por lo que en el caso más que previsible de grandes cuellos de botella en el gasto de Comunidades Autónomas o ayuntamientos, supone un recurso tentador para cualquier gobierno central para absorber vía el MRR buena parte de los fondos estructurales inicialmente destinados a las regiones, con la ventaja de no exigir cofinanciación. El MRR es, por tanto, una espada de Damocles que pende de la política de cohesión y de las regiones ${ }^{49}$.

\section{EL «PLAN ESPAÑA PUEDE»Y EL REAL DECRETO-LEY 36/2020, DE 30 DE DICIEMBRE}

El presidente del Gobierno, Pedro Sánchez, presentó el 7 de septiembre de 2020 las líneas generales del Plan de Recuperación, Transformación y Resiliencia («Plan España Puede») ${ }^{50}$ cuya discusión comenzó con la Comisión Europea a mediados de octubre previa a su envío definitivo a la Comisión Europea antes de finales de abril de 2020. El 26 de ese mes de octubre, la presidenta de la Comisión, Úrsula von der Leyen, se reunió con la Conferencia de Presidentes para discutir dicho plan ${ }^{51}$.

Es precisamente la gobernanza de dichos fondos el principal desafío del mal llamado Plan de Recuperación. Hay que tener en cuenta que, al final del periodo actual 20142020, aún no había ha gastado ni la mitad de los 40.000 millones de Fondos Estructurales (regionales, sociales, rurales) asignados a España ${ }^{52}$.

Contrariamente a la enorme expectativa pública que ve en la llegada de esos fondos un alivio inmediato, de la primera partida del MRR que el Gobierno quiere compro-

48 J. Bachtler, C. Méndez y F. Wishdale, «Will Cohesion Policy recover from covid? An Initial Assessment», European Regional Policy Research Consortium Paper 20/3, European Policies Research Centre, 2020.

49 F. Molica y E. Lleal FonTÀs, «Next Generation EU: a threat to Cohesion Policy?», Technical note, Conference of Peripheral Maritime Regions, diciembre de 2020.

50 Gobierno de España, España Puede. Plan de Recuperación, Transformación y Resiliencia de la Economía, 2020.

51 Las discusiones entre presidentes autonómicos exigiendo porcentajes fijos del RRF para cubrir déficit de caja o gasto corriente, como se escuchó en la Conferencia de Presidentes de San Millán de la Cogolla y repetida y aumentada el 26 de octubre en el Senado, en presencia de la presidenta de la Comisión Von der Leyen, la polémica por el reparto autonómico del REACT UE o la disputa por el reglamento de la nueva Comisión Sectorial para el MRR no auguran un clima edificante en la llamada cogobernanza del NGEU.

52 S. PAZOS-VIDAL, «REACT EU and Reality», Agenda Pública, 17 de junio de 2020, http:/lagendapublica. elpais.com/react-eu-and-reality/. 
meter en 2021 (25.000 millones), la UE solo remitirá este año el 13 por 100 asignado a España para 2020-2021. El resto será reembolsado en función de que se presenten proyectos que cumplan con los hitos marcados.

TABLA I. FONDOS EUROPEOS PARA ESPAÑA 2021-2026/2027 (datos actualizados a enero 2021, millones de euros)

\begin{tabular}{|c|c|c|c|c|c|c|c|}
\hline \multicolumn{2}{|c|}{$\begin{array}{c}\text { Fondos Estructurales } \\
\text { 2021-2027 }\end{array}$} & \multicolumn{3}{c|}{$\begin{array}{c}\text { Plan de Recuperación } \\
\text { 2021-23/26 }\end{array}$} \\
\hline $\begin{array}{r}\text { Subvenciones, cofinanciables, mayormente gestionados } \\
\text { por Programas Operativos de las CCAA }\end{array}$ & $\begin{array}{c}\text { Subvenciones } \\
\text { - gestionadas } \\
\text { como FFEE- } \\
\text { CCAA } \\
\text { M. Sanidad }\end{array}$ & $\begin{array}{c}\text { Subvenciones } \\
\text { Ministerios, } \\
\text { Agencias } \\
y \text { PERTES }\end{array}$ & $\begin{array}{c}\text { Créditos } \\
\text { NGEU } \\
(4,2 \% \\
\text { RNB }\end{array}$ \\
\hline FEADER & FSE & FTJ & $\begin{array}{c}\text { INTE- } \\
\text { RREG }\end{array}$ & FEDER & REACT & MRR & \\
\hline 7.800 & 9.896 & $\begin{array}{c}452 \\
+339\end{array}$ & 606 & 20.886 & $\begin{array}{c}10.000 \\
\text { (CCAA) } \\
+2.436(\mathrm{MS})\end{array}$ & $\begin{array}{c}40.000+ \\
20.000 \\
(2023)\end{array}$ & 52.248 \\
\hline
\end{tabular}

Fuente: Comisión Europea, Ministerio de Hacienda y elaboración propia.

El Gobierno estima en el Libro Amarillo ${ }^{53}$ de los Presupuestos Generales del Estado (PGE) 2021 que dicho plan incluirá 25.000 millones de transferencias del Mecanismo de Recuperación y Resiliencia (MRR) en 2021, que se incorporan al techo de gasto. La asignación total de dicho Mecanismo (en realidad, un fondo) para España son 59.168 millones, de los cuales hay que comprometer (que no gastar) dos tercios en 2021 y 2022. Si ese fuera el caso, entonces se autorizaría comprometer los 15.688 restantes en 2023. Como ya se ha dicho el gasto, sin embargo, puede ejecutarse hasta 2026, es decir, un año antes del Presupuesto ordinario de la UE, el Marco Financiero Plurianual (MFP) 2021-2027.

Además, como se informó en el Consejo de Política Fiscal y Financiera de enero, la mayor parte de los 12.436 millones del programa REACT UE, como fondos estructurales sui generis que son, se destinarán a las Comunidades Autónomas, aunque habrá 2.436 millones para el Ministerio de Sanidad. En 2021-2020 las Comunidades gestionarán como anteriormente buena parte de los 35.000 millones del Fondo Social Europeo (FSE) y el Fondo Europeo de Desarrollo Regional (FEDER) y de los 7.800 millones del Fondo Europeo Agrícola de Desarrollo Rural (FEADER).

La base, tanto para la elaboración del Acuerdo de Asociación de los Fondos Estructurales como del Plan de Recuperación, es el Informe de País de la Comisión Europea de

53 Ministerio de Hacienda, Presentación del Proyecto de Presupuestos Generales del Estado 2021, Ministerio de Hacienda, Madrid, 2020. 
2019, cuyo "Anexo D» ${ }^{54}$ analiza lo que la Comisión estima que son las áreas y temas en los que España debería centrar sus inversiones financiadas por la UE para 2021-2027. El Reino de España asume y actualiza cada año este tipo de compromisos en su Programa Nacional de Reformas ${ }^{55}$.

Como se ve en la tabla más abajo, si comparamos los ejes prioritarios del Plan de Recuperación — que no se corresponden exactamente con los seis que figuran en el MRR, aunque sí lo hacen más directamente con las ya citadas siete Iniciativas Emblemáticas propuestas por la Comisión - vemos una gran identidad con los cinco Objetivos Políticos que constituyen las prioridades de los Fondos Estructurales 2021-2027.

TABLA II. COMPARACIÓN DE LAS PRIORIDADES DEL MRR ESPAÑOL Y DE LOS OBJETIVOS PRIORITARIOS DE LOS FONDOS ESTRUCTURALES

\begin{tabular}{|l|l|}
\hline \multicolumn{1}{|c|}{$\begin{array}{c}\text { Plan de Recuperación ejes prioritarios } \\
\text { (\% del total asignado, en su caso) }\end{array}$} & \multicolumn{1}{|c|}{$\begin{array}{c}\text { Fondos Estructurales } 5 \text { Objetivos prioritarios } \\
\text { (\% del total asignado, en su caso) }\end{array}$} \\
\hline $\begin{array}{l}\text { Agenda urbana y rural y lucha contra la despo- } \\
\text { blación }(16 \%) .\end{array}$ & $\begin{array}{l}\text { Objetivo Político 5, «Una Europa más próxi- } \\
\text { ma al ciudadano». }\end{array}$ \\
\hline $\begin{array}{l}\text { Cuidado de los ecosistemas naturales. Fondo de } \\
\text { inversiones verdes (12\% de los recursos). }\end{array}$ & $\begin{array}{l}\text { Objetivo Político 2, «Una Europa más verde», } \\
30 \% \text { FEDER. } \\
\text { Objetivo Político 3, «Una Europa más conec- } \\
\text { tada». }\end{array}$ \\
\hline Transición energética (9\%). & $\begin{array}{l}\text { Objetivo Político 2, «Una Europa más verde», } \\
30 \% \text { FEDER. }\end{array}$ \\
\hline $\begin{array}{l}\text { Modernización de las administraciones públicas } \\
\text { (5\%). }\end{array}$ & $\begin{array}{l}\text { Objetivo Político 5, «Una Europa más próxi- } \\
\text { ma al ciudadano». }\end{array}$ \\
\hline $\begin{array}{l}\text { Modernización de la industria y el turismo } \\
(17 \%) .\end{array}$ & $\begin{array}{l}\text { Objetivo Político 1, «Una Europa más inteli- } \\
\text { gente», 25-55\% FEDER según CCAA. } \\
\text { Objetivo Político 3, «Una Europa Más Conec- } \\
\text { tada». } \\
\text { Objetivo Político 5, «Una Europa más próxi- } \\
\text { ma al ciudadano». }\end{array}$ \\
\hline Pacto por la Ciencia (17 \%). & $\begin{array}{l}\text { Objetivo Político 1, «Una Europa más Inteli- } \\
\text { gente», 25-55\% FEDER según CCAA. } \\
\text { Objetivo Político 4, «Una Europa más social», } \\
\text { FSE. }\end{array}$ \\
\hline
\end{tabular}

54 COMISIÓN EUROPEA, Informe sobre España 2019 con un examen exhaustivo en lo que respecta a la prevención y la corrección de los desequilibrios macroeconómicos, SWD (2019) 1008 final, Bruselas, 27 de febrero de 2019.

55 Gobierno DE EsPaÑA, «Actualización del Programa de Estabilidad 2020 Reino de España, 2020», https:/lec.europa.eu/info/sites/info/files/2020-european-semester-stability-programme-spain_en.pdf. 


\begin{tabular}{|l|l|}
\hline \multicolumn{1}{|c|}{$\begin{array}{c}\text { Plan de Recuperación ejes prioritarios } \\
\text { (\% del total asignado, en su caso) }\end{array}$} & \multicolumn{1}{|c|}{$\begin{array}{c}\text { Fondos Estructurales 5 Objetivos prioritarios } \\
\text { (\% del total asignado, en su caso) }\end{array}$} \\
\hline $\begin{array}{l}\text { Educación; incluida la formación continua } \\
(18 \%) .\end{array}$ & $\begin{array}{l}\text { Objetivo Político 1, «Una Europa más Inteli- } \\
\text { gente», 25-55 \% FEDER según CCAA. } \\
\text { Objetivo Político 4, «Una Europa más social», } \\
\text { FSE. }\end{array}$ \\
\hline Servicios de atención a mayores (6\%). & $\begin{array}{l}\text { Objetivo Político 4, «Una Europa más social», } \\
\text { FSE. }\end{array}$ \\
\hline Desarrollo del deporte y la cultura (1\%). & $\begin{array}{l}\text { Objetivo Político 4, «Una Europa más social», } \\
\text { FSE. }\end{array}$ \\
\hline
\end{tabular}

Fuente: Comisión Europea, Ministerio de Hacienda y elaboración propia.

En todo caso, dada la enorme cantidad de fondos movilizados (60.000 MRR, 12.000 REACT con 40.000 FFEE) la complementariedad cuando no identidad de los proyectos y costes elegibles y gasto hace necesaria una programación y ejecución coordinada del MRR, FEDER, FSE y FEADER en España.

Sin embargo, y en contraste con el enorme interés púbico y académico (como atestigua la bibliografía de este artículo) por el Plan de Recuperación español, se constata una la falta de discusión sobre el Acuerdo de Asociación (2021-2027 para el FEDER y el FSE) y sobre el Plan Estratégico PAC para el FEADER. Además, los Programas Operativos Autonómicos (y en su caso, plurirregionales) que fijan las prioridades y gestión territorial delegada de dichos fondos debieran estar acordados a finales de año. Poco se sabe de los mismos pese a ser dinero que, a diferencia del MRR que depende del acceso a los mercados financieros y el pago por hitos, con los Fondos Estructurales y FEADER España ya tiene garantizado que sí va a recibir del MFP.

Por tanto, lo lógico sería que tanto el Plan de Recuperación como el Acuerdo de Asociación y el Plan Estratégico PAC y sus programas operativos se desarrollasen al unisono y en coherencia. No parece que vaya a ser el caso.

Un aspecto a destacar es el hecho que si bien sucesivos informes de la Comisión en el marco del Semestre Europeo han puesto el dedo en la llaga en débil capacidad de adaptación, respuesta ante crisis, interoperabilidad y transparencia de las administraciones públicas. Algo que la crisis del coronavirus ha demostrado ser tan imperativo como ha destacado el manifiesto de Longo, del Pino, Lapuente, y muchos otros ${ }^{56}$. De hecho, como reza el considerando 15 del Reglamento MRR, son un elemento horizontal y clave a las reformas en el caso español. Sin embargo, el Real Decreto-ley 36/2020, de 30 de diciembre, se centra en solventar con una norma ad hoc de excepción esencialmente

56 F. Longo, E. del Pino Matute y V. Lapuente, «Por un sector público capaz de liderar la recuperación", Agenda Pública, 2 de junio de 2020, https://agendapublica.es/por-un-sector-publico-capaz-de-liderar-larecuperacion/. 
para la absorción del MRR ${ }^{57}$. De hecho, el Plan de Recuperación solo dedica un 5 por 100 específicamente a la modernización y capacitación de las administraciones. El plan alemán prevé el doble, por ejemplo.

La llamada cogobernanza —o en su definición académica, gobernanza multinivel- ${ }^{58}$ del Plan está muy perfilada en la parte superior (Conferencias sectoriales, Conferencia de Presidentes), así como la novedosa centralización de decisiones en Moncloa (Comisión para la Recuperación, Transformación y Resiliencia, que presidirá el presidente del Gobierno apoyado por Departamento de Asuntos Económicos y G20 del Gabinete de la Presidencia que será responsable con un Comité Técnico que dará apoyo a esta Comisión), confirmando la hipótesis de Buti y Polli que precisamente preveían este supuesto en los Estados miembros con coaliciones débiles e inestable pluripartidismo, como es actualmente el caso español ${ }^{59}$.

La participación de las Comunidades Autónomas, a mayores de las Conferencias de Presidentes, se formaliza por la nueva Conferencia Sectorial del Plan de Recuperación, Transformación y Resiliencia, con las comunidades y ciudades autónomas, presidida por el ministro/a de Hacienda, y a la que se podrá invitar la FEMP, y que estar apoyada a nivel técnico por la nueva Comisión de Coordinadores de Fondos Europeos.

El Plan y, posteriormente el Real Decreto-ley 36/2020, confirma al Ministerio de Hacienda como autoridad responsable ante las instituciones europeas también para el MRR, ya lo era para los Fondos Estructurales mediante la Dirección General de Fondos Europeos, a la que ahora se añade una nueva Dirección General del Plan y del Mecanismo de Recuperación y Resiliencia, pasando la titular de la Dirección General de Fondos a ocupar la nuevamente creada, Secretaría General de Fondos Europeos. Todo lo cual se antoja en un modelo de coordinación demasiado liviano para evitar los silos que por propia inercia existirán entre los diferentes fondos debido a su tamaño y al hecho que dependen direcciones generales diferentes de la Comisión Europea. Si bien la posibilidad de que el MRR se gestionase desde Economía (a la sazón la cartera responsable del Semestre Europeo) y a pesar de cierta especulación, nunca se optó por crear una Agencia separada como el caso de las agencias de cohesión en Portugal, Italia o Rumanía. El riesgo es, como apunta Enrique Feás, la cultura de Hacienda es la del Cuerpo Superior de Interventores y Auditores del Estado, es decir, está destinada a asegurase de la ejecución del gasto, no si la inversión sirve a realizar cambios estructurales ${ }^{60}$.

57 A. J. TAPia Hermida, «El plan de inversión que cambiará Europa y España en el próximo sexenio: el instrumento de recuperación de la Unión Europea y el Plan de Recuperación, Transformación y Resiliencia de España», La Ley Unión Europea, núm. 88, 2021.

58 L. HoOghe y G. MARKS, «Unravelling the central state, but how? Types of multi-level governance», American Political Science Review, vol. 97, núm. 2, 2003, pp. 233-243.

59 M. BuTi y O. Polli, «Veto player theory and the governance of the Recovery and Resilience Facility», VOXEU, 11 de febrero de 2021, https://voxeu.org/article/veto-player-theory-and-governance-recovery-and-resilience-facility.

60 E. FEÁs, «Lo que sabemos, y lo que no, del Plan de Recuperación Enrique Feás», Vozpopuli, 2 de febrero de 2021, https://www.vozpopuli.com/opinion/bruselas-recuperacion-sanchez_O_1432656938.html. 
Por último, la gobernanza tiene grandes asimetrías, en los Fondos Estructurales el Acuerdo de Asociación se estructura como se ha dicho en Programas Operativos para cada fondo y para cada Comunidad Autónoma (amén de algún programa plurirregional como el caso de la agenda de regeneración urbana EDUSI dotado con 5 por 100, ahora 8 por 100 , del FEDER) ${ }^{61}$ o en algunos casos la delegación al nivel municipal y provincial desde los Programas Operativos vía las Inversiones Territoriales Integradas subautonómicas (ITI Teruel) o interautonómicos (ITI Azul), o los Grupos de Acción Local LEADER-CLLD ${ }^{62}$.

Por el contrario, en el caso del MRR y el Plan de Recuperación, el Real Decretoley 36-2020 apenas detalla cómo serán los Convenios con Comunidades Autónomas y AA.LL., por lo que a diferencia de los Fondos Estructurales que tienen una estructura muy tasada nos arriesgamos al extremo contrario, al priorizar acuerdos ad hoc, acabemos en un escenario en el que las duplicidades, incoherencias o silos departamentales en y entre niveles de gobierno se multipliquen aún más.

\section{El Real Decreto-ley 36/2020: un instrumento insuficiente e incompleto}

El muy esperado y ampliamente filtrado Real Decreto-ley 36/2020, de 30 de diciembre, por el que se aprueban medidas urgentes para la modernización de la Administración pública y para la ejecución del Plan de Recuperación, Transformación y Resiliencia, ciertamente crea unos procedimientos ad hoc para acelerar el gasto del MRR, aspecto criticado en el Dictamen del Consejo de Estado ${ }^{63}$, en eso sí se ha aprendido de la muy lenta ejecución de los Fondos Estructurales. Sorprendentemente, e incomprensiblemente, ese aligeramiento normativo no se le va a aplicar (necesariamente) a los Fondos Estructurales, siendo como es perfectamente posible hacerlo porque, como decimos, la base legal y de gestión financiera es la misma para MRR que para Fondos Estructurales ${ }^{64}$.

61 S. de Gregorio Hurtado y M. GonzÁlez Medina, «Las EDUSI en el contexto de las políticas de regeneración urbana en España (1994-2018)", WPS Review International on Sustainable Housing and Urban Renewal: RI-SHUR, núm. 6, 2017, pp. 54-80.

62 S. KAH, «Implementing ERDF Through CLLD: Experiences So Far», European Structural and Investment Funds Journal, vol. 7, núm. 1, 2019, pp. 47-57; M. FERRY, S. KAH y J. BACHTLER, «Integrated territorial development: new instruments -new results?», IQ-Net Thematic Paper, 42(2), junio de 2018.

63 Consejo DE Estado, Dictamen núm.783, 21 de diciembre de 2020, https://consejo-estado.es/ pdfl783_2020.pdf.

Una muestra de las múltiples críticas al contenido y los modos del real decreto-ley se puede ver en: M. P. BATET, La urgencia y la emergencia en la tramitación de los fondos de recuperación, 21 de marzo de 2021, https:// lapartecontratante.blog/2021/03/21/la-urgencia-y-la-emergencia-en-la-tramitacion-de-los-fondos-de-recuperacionpor-m-p-batetl.

M. A. Blanes, La ocultación de las observaciones esenciales del Consejo de Estado al Real Decreto-ley sobre los Fondos Europeos y su posible inconstitucionalidad, https://miguelangelblanes.com/2021/03/01/la-ocultacion-delas-observaciones-esenciales-del-consejo-de-estado-al-real-decreto-ley-sobre-los-fondos-europeos-y-su-posible-inconstitucionalidad/.

64 Para una primera aproximación en profundidad a este real decreto-ley, con puntos de vista más expansivos sobre el alcance del Real Decreto-ley 36/2020 al conjunto de fondos europeos, vid. C. CAMPOS ACUÑA 
Por un lado, es importante notar que el art. 2.2 del real decreto-ley establece que el Capítulo III del Título III (planificación estratégica), y los Capítulos II (Especialidades en la Tramitación de los procedimientos), III (Especialidades en materia de contratación), IV (Medidas de agilización de los convenios financiables con fondos europeos), $\mathrm{V}$ (Medidas de agilización de las subvenciones financiables con fondos europeos) y VI (Especialidades en materia de evaluación ambiental) del Título IV, así como el art. 46, no solo se aplican a las actuaciones financiables por el NGEU, sino también a las de los Fondos Estructurales y el FEADER.

Vista la perspectiva del Derecho de la UE esta redacción resulta harto confusa. Si bien es cierto que tomas aquellas medidas de agilización del uso de recursos humanos y digitales del Título III parecen ser de aplicación general para todos los fondos, en buena parte de los artículos antes mencionados, y donde se menciona explícitamente el Plan de Recuperación, Transformación y Resiliencia, surge la duda de en qué medida se aplican a los Fondos Estructurales y al FEADER ya que dicho Plan no abarcará dichos fondos (ya que están cubiertos por instrumento equivalente y separado, el Acuerdo de Asociación para los Fondos Estructurales y el Plan Estratégico PAC para el FEADER). Estos tres planes nacionales deben remitirse separadamente a la Comisión Europea. Asumiendo que esta redacción del real decreto-ley no esté basada en el desconocimiento, la hipótesis es bien que esté dando una interpretación expansiva del ámbito de aplicación dichos artículos a los Fondos Estructurales y FEADER aunque no se mencionen en el articulado, a renglón seguido del Plan de Recuperación. La interpretación alternativa sería que este art. 2.2 del real decreto-ley estaría dando base jurídica al posible trasvase de Fondos Estructurales o del FEADER al MRR vía el art. 7 del Reglamento MRR.

En vez de una asignación por Programas Operativos como el caso de los Fondos Estructurales (es decir, una asignación global de una parte del fondo a normalmente una Comunidad Autónoma ${ }^{65}$ para uso en una serie de ejes de diversos tipos de actuaciones supuestamente coordinadas entre sí), el Plan de Recuperación y este real decreto-ley priorizan el uso de convenios, agilizando mediante el Título II su tramitación. Dichas medidas también se aplicarán a las agencias estatales, que han sido reintroducidos en la Administración pública mediante Ley de Presupuestos Generales

(ed.), La gestión de los Fondos Next Generation. Claves de la revolución administrativa, Wolters Kluwer, Madrid, 2021.

65 En este sentido, la vinculación del art. 44 del real decreto-ley sobre ejecución de los créditos que hayan de distribuirse territorialmente a favor de las Comunidades Autónomas al art. 86 de la Ley 47/2003, de 26 de noviembre, General Presupuestaria, parece ser el mecanismo por el que se va a intentar asegurar la constitucionalidad del real decreto-ley, ya que si bien las Comunidades Autónomas podrían alegar no haber sido involucradas en el diseño del Plan y los proyectos, serían ellas las encargadas a través de la Conferencia Sectorial creada por este real decreto-ley de la ejecución del gasto en el ámbito de su competencia. Para una discusión más amplia sobre este tema vid. R. JIMÉNEZ AsENSIO, El Reglamento (UE) del Mecanismo de Recuperación y Resiliencia: 7 Lineas-Fuerza y una Apostilla, https://rafaeljimenezasensio.com/2021/02/15/el-reglamento-ue-de-recuperacion-yresiliencia-7-lineas-fuerza-y-una-apostillal. 
del Estado para el año 2021 —y de hecho el nuevo Instituto para la Transición Justa y posiblemente en la nueva política de reto demográfico— ${ }^{66}$ están destinadas a gestionar parte de los fondos.

En el Capítulo III del Título II se recoge una nueva figura de colaboración públicoprivada: los Proyectos Estratégicos para la Recuperación y Transformación Económica (PERTES). Este tipo de grandes proyectos cuya ejecución puede impactar a los indicadores macroeconómicos se ajustan a la finalidad buscada en el MRR y es poco probable que las autoridades locales tengan un rol destacado en los mismos.

En todo caso, ni en el caso de los Convenios, Agencias o PERTES estamos en los supuestos de gobernanza territorial de los Fondos Estructurales en las que los fondos se asignan territorialmente de antemano para una multiplicidad de proyectos. Más confuso aún, el «libro amarillo» de los PGE 2011 indica que efectivamente los PGE ya han preasignado más de 10.000 millones del MRR de 2021 — es decir, la mitad- a Comunidades Autónomas y a las autoridades locales ${ }^{67}$.

Ahora bien, a la espera de la metodología para seleccionar PERTES y Convenios que es de esperar se detalle con rigor en el Plan de Recuperación que se envíe a Bruselas en abril de 2021 (como así lo pide art. 18 MRR), el real decreto-ley es mudo en la forma en la que se escogerá o priorizará unos sobre otros ${ }^{68}$. Todo se fía aparentemente a la estructura de gobernanza del Título III, Capítulo III, Comisión para la Recuperación, Transformación y Resiliencia, que presidirá el presidente del Gobierno, apoyada por Comité Técnico para el Plan de Recuperación, Transformación y Resiliencia y el propio presidente por su Departamento de Asuntos Económicos y G20 del Gabinete de la Presidencia del Gobierno, que realizará el seguimiento del Plan de Recuperación, Transformación y Resiliencia.

Como decimos, la gobernanza territorial se basa en una nueva Conferencia Sectorial Plan de Recuperación, Transformación y Resiliencia (art. 19 del real decreto-ley) presidida por la ministra de Hacienda y los consejeros autonómicos competentes, y en donde se "podrá convocar» a los representantes designados por la Federación Española de Municipios y Provincias (art. 19.2 del real decreto-ley). Además, los ministerios podrán crear foros de participación y grupos de alto nivel (art. 17) y otros específicos para las organizaciones del diálogo social (art. 19).

${ }^{66}$ Así se apunta ya en las Directrices para el reto demográfico tomando inspiración en las agencias de desarrollo regional británicas. O en las llamadas Oficinas de Lucha contra la Despoblación, que se discutirá más adelante.

Comisionado para el Reto demográfico Directrices Generales de la Estrategia Nacional frente al Reto Demográfico Ministerio de Política Territorial y Función Pública 2019.

67 Ministerio de Hacienda, Presentación del Proyecto de Presupuestos Generales del Estado 2021, Ministerio de Hacienda, Madrid, 2020.

68 Es por eso que no dejó de causar sorpresa cuando el presidente del Gobierno anuncia ya la concesión de un PERTE concreto antes de que se conozca siquiera la versión definitiva del Plan de Recuperación. Vid. P. SÁNCHEZ, «El primer PERTE de España: el coche eléctrico», El País, 7 de marzo de 2021. 
A pesar de todo de lo anterior, la participación de las administraciones territoriales y actores sociales prevista para el MRR no parece que vaya a ser, en la práctica, radicalmente diferente o menos activa que la que tuvo lugar en la preparación del Acuerdo de Asociación 2014-2020 ${ }^{69}$, o respecto a la participación de autonomías y actores sociales en el seguimiento del programa operativo plurirregional FEDER España 2014-2020, donde estuvieron representados y participaron de los comités de seguimiento en virtud del ya citado principio de partenariado ${ }^{70}$.

Con todo, y es de suponer en parte por la premura, en vez de realizarse una consulta estructurada como sucede con la preparación de los Fondos Estructurales para el MRR, se ha optado por que cada ministerio lance una serie de "manifestaciones de interés", sin ningún valor jurídico a modo de concurso de ideas para a partir de las mismas se puedan poder identificar las necesidades a partir de las cuales diseñar las convocatorias que lanzarán cada uno de los diferentes ministerios.

Como señalaba Hidalgo, es imprescindible ver los fondos europeos no como meras dotaciones presupuestarias, sino como herramientas de transformación. Sin embargo, como bien apuntan Jiménez Asensio y Vázquez Matilla, la estructura anticipada por el real decreto-ley es demasiado desnuda para articular procesos realmente transformadores $^{71}$. Se perdería además, como teme Ramió, una nueva oportunidad de transformar la Administración pública, ya que el real decreto-ley no va al meollo de la cuestión ${ }^{72}$. Además, no olvidemos, como escribió Toni Roldán, que dirá el contribuyente neto holandés al que le recorten la pensión por tener Países Bajos que pagar la parte del crédito mancomunado de la UE, para al final hacer proyectos elefantiásicos con el MRR en España $^{73}$.

\section{LA DIMENSIÓN LOCAL DEL PLAN DE RECUPERACIÓN}

Que la gestión y gobernanza sea, de jure al menos, más centralizada que en los Fondos Estructurales el Reglamento MRR no impide que si el gobierno del Estado miem-

69 Cfr. «Medidas de Consulta del Acuerdo de Partenariado», pp. 258-259, https://www.dgfc.sepg.hacienda. gob.es/sitios/dgfcles-ES/ipr/fcp1420/p/pa/Documents/20190215_AA_Espa\%C3\%B1a_2014_2020_Vdef.pdf.

70 Ministerio De HaCiendA, "Anexo Ciudadanía para el Programa Operativo FEDER Plurirregional de España 2014-2020. Año 2019», 2019, https://www.dgfc.sepg.hacienda.gob.es/sitios/dgfcles-ES/ipr/fcp1420/gs/ feder/cs/Documents/INFORME_CIUDADANIA_POPE-2019_validado.pdf. Cfr. Miembros del Comité de Seguimiento, https://www.dgfc.sepg.hacienda.gob.es/sitios/dgfcles-ES/ipr/fcp1420/gs/feder/cs/Documents/Miembros_ CdS_POPE.pdf.

${ }_{71}$ R. Jiménez Asensio y F. J. VÁzquez Matilla, «La carrera por los fondos europeos», El Confidencial, 26 de enero de 2021.

72 C. RAMIÓ, «La reforma administrativa para la gestión de los fondos europeos. ¿A la segunda la vencida? (I)", EsPúblico, 3 de febrero de 2021, https://www.administracionpublica.com/la-reforma-administrativapara-la-gestion-de-los-fondos-europeos-a-la-segunda-la-vencida-i/.

73 T. RoldÁn, «Poisonous politics lurk behind the EU recovery fund», Financial Times, 20 de diciembre de 2020 . 
bro lo considera se territorialice el gasto y parte de la gestión. Ese parece ser el caso en España, donde el citado «libro amarillo» de los PGE $2021^{74}$ confirma que se destinarán 8.000 millones del REACT UE a las Comunidades Autónomas (lógico, ya que como hemos dicho, REACT UE no es más que una partida adicional de Fondos Estructurales, que simplemente ha sido financiada fuera del MFP a través de ese mecanismo de endeudamiento que es el NGEU).

Además, se destinarán 10.793 millones de los «fondos de recuperación» (entendemos el MRR) para las Comunidades Autónomas y 1.489 millones a las entidades locales (EELL) para que aborden actuaciones en su ámbito competencial. Esos totales están divididos por departamentos, 2.873 millones corresponden a políticas medioambientales del Ministerio de Transición Ecológica y 1.380 millones de políticas de vivienda del Ministerio de Transporte y ya se han preasignado a las Comunidades (el resto estaba pendiente de asignación en el momento de tramitación de los PGE), todo ello «sin perjuicio de lo que se decida en los foros de diálogo y entendimiento con las Comunidades Autónomas, como las conferencias sectoriales» ${ }^{75}$.

Es decir, al igual que los anuncios de los PERTE antes de la entrada en vigor el Reglamento MRR y de que se acuerde la metodología de priorización de proyectos en el Plan de Recuperación, y de que se creen los organismos de coordinación con las autoridades territoriales previstos en el Real Decreto-ley 36-2020 ya se territorializa la mitad de las partidas del NGEU (MRR y REACT). Si bien hay razones de premura y de desconfianza institucional, habida cuenta la postura poco razonable de muchas Comunidades Autónomas que llegaron a exigir no solo al gobierno, sino a la presidenta Von der Leyen un reparto de los fondos como si fuesen subvenciones a fondo perdido para financiar gasto corriente, lo cierto es que parece que nos encontramos con el viejo adagio del despotismo ilustrado: «todo por los territorios pero sin ellos» ${ }^{76,77}$.

Hay que entender que lo que se busca con el MRR, y por eso lo aprobaron los contribuyentes netos o frugales. Es una alternativa a los Fondos Estructurales, extendiendo para los 27 Estados miembros las ventajas del Fondo de Cohesión, que ya beneficia a los Estados miembros con el 90 por 100 del PIB europeo, como le pasó España en su día, y que se destina para grandes proyectos tractores de país gestionados centralizadamente por los gobiernos estatales.

Es por eso por lo que esta preasignación del Gobierno a las Comunidades Autónomas al MRR puede resultar engañosa o como menos excesivamente optimista. No solo porque al final la Comisión no quiera que tengan un rol tan grande, sino uno muy

74 Ministerio de Hacienda, op. cit., pp. 420-421.

75 Ibid.

76 Vid. supra, CoR.-CMRE 2021.

77 Como se evidencia en el estudio CoR-CMRE (2021, vid. supra) —el autor ha sido partícipe indirecto de su elaboración-, ni en Estados de gran tradición consociativo como Países Bajos, ni siquiera federales como Alemania, el rol de los niveles subestatales en la preparación de los planes MRR ha sido relevante. 
tasado como parte de grandes proyectos de Estado — como los que el real decreto-ley concibe para el sector privado como los PERTE o las revitalizadas agencias, como el caso de la nuevo Instituto para Transición Justa- . Hay que ser cautos por tanto con las expectativas de las varias expresiones de interés que tanto Comunidades Autónomas como varios ministerios han hecho para optar al MRR ya que pueden resultar un espejismo: la Comisión no quiere que se financien con el MRR pequeños proyectos que de todos modos son ya elegibles con los Fondos Estructurales, ni quiere meterse en auditar cientos e incluso decenas de autoridades delegadas.

Además, la Comisión no tiene los mismos incentivos para ser más flexible con los proyectos del MRR como sí hace con los FFEE, sobre todo al final de cada periodo plurianual. Los Fondos Estructurales hay que gastarlos porque son dineros que vienen de las arcas de los contribuyentes netos, y si no se gastan, vuelven a esas haciendas nacionales. Pero, en el caso del MRR, ese dinero la UE tiene que pedirlo y endeudarse - endeudarnos todos - en los mercados financieros, por lo que, a ojos de la Comisión, no tienen tanto incentivo para hacer la vista gorda con proyectos elefante blanco del MRR.

Como hemos visto, en lugar de un proceso negociado de programas - principio de asociación - para el MRR, se ha procedido a un proceso de consulta vía «manifestaciones de interés», doce hasta el momento. Como ya se ha dicho, no es un proceso jurídicamente vinculante ni genera derechos algunos ni se inicia cómo se va a usar esa información. Para añadir más confusión, cada ministerio organiza las suyas, con calendarios y métodos propios. Sin embargo, al mismo tiempo los PGE anuncian toda una serie de medias, como el caso del Ministerio de Transición Ecológica y Reto Demográfico, que anuncia, para pueblos de menos de 5.000 habitantes, un presupuesto de 350 millones del MRR en 2021 a actuaciones de rehabilitación de vivienda y regeneración urbana en zonas en declive demográfico y otros 100 para depuradoras y saneamiento municipal, otros 300 millones en tres años para la banda ancha, Instituto para la Transición Justa, dependiente de dicho ministerio, prevé contar con un fondo propio de la UE de 85 millones en 2021 (FTJ) que tendrá impacto directo en reto demográfico y curiosamente solo 19 millones para la nueva Secretaría General de Reto Demográfico para labores de dinamización y coordinación (como las llamadas oficinas de despoblación) ${ }^{78}$.

Sin embargo, estos montantes de alrededor de 569 millones de fondos europeos para reto demográfico (en un sentido amplio) son parte de 2.500 millones que, según este ministerio, todo el Gobierno realizará con cargo al MRR para proyectos de reto de-

78 Ministerio PARA la Transición ECOlÓgICA y El RETO DEMOgRÁFICO, "MiTECO incrementa su presupuesto un 132 por 100 para impulsar la transición ecológica, avanzar hacia la neutralidad climática en 2050 y abordar el reto demográfico", 30 de octubre de 2020, https:/www.miteco.gob.es/es/prensa/ultimas-noticias/ el-miteco-incrementa-su-presupuesto-un-132-para-impulsar-la-transici\%C3\%B3n-ecol\%C3\%B3gica-avanzar-hacia-la-neutralidad-clim\%C3\%A1tica-en-2050-y-abordar-el-ret/tcm:30-516034; id., "Plan de recuperación, 130 medidas frente al reto demográfico», 2021. 
mográfico y que, como veremos, solo unas pocas semanas después se elevaron a 10.000 millones como resultas de la segunda reunión de la Comisión Delegada para el Reto Demográfico, en la que se ha aprobado el Plan de Medidas ante el Reto Demográfico, que contará con una inversión superior a 10.000 millones de euros —en torno al 10 por 100 del Plan de Recuperación, Transformación y Resiliencia- en un total de 130 actuaciones orientadas a luchar contra la despoblación y garantizar la cohesión social y territorial ${ }^{79}$.

Tampoco parece probable que este anuncio del Gobierno fuese hecho en concertación con las administraciones territoriales en la Conferencia Sectorial. Sin embargo, casi a renglón seguido de lo anterior, la ministra anuncia un acuerdo con la Junta de Gobierno de la FEMP por la cual esos 569 millones se gestionarían directamente por las corporaciones locales de más de 50.000 habitantes y «con acompañamiento de las diputaciones, consells y cabildos» para los de menos de 50.000, comprometiéndose a «buscar fórmulas de coordinación» para transferir directamente a los ayuntamientos más fondos europeos ${ }^{80}$. Sin embargo, se desconoce cómo se hará ese reparto, si habrá negociación, concurrencia competitiva o procesos colaborativos. En definitiva, si estamos ante un reparto de rentas europeas (rent seeking) o si se buscan grandes proyectos integrados a nivel de país, como busca el MRR.

En definitiva, con tanto baile de cifras con una arquitectura de gobernanza tan difusa el escepticismo sea un sentimiento natural entre las autoridades locales.

De todas las manifestaciones de interés (12 hasta finales de marzo de 2020), la que más interés ha suscitado entre ayuntamientos y diputaciones es la de la recientemente creada Secretaría General para el Reto Demográfico que suscitó grandes dudas entre las diputaciones y ayuntamientos medianos al estar centrada en ayuntamientos de menos de 5.000 habitantes ${ }^{81}$, estar diseñada para la identificación de ideas aisladas preferente-

79 Ministerio para la Transición Ecológica y el Reto Demográfico, «El Plan de Medidas ante el Reto Demográfico destinará más de 10.000 millones y 130 políticas activas a luchar contra la despoblación y garantizar la cohesión territorial y social», 16 de marzo de 2021, https://www.miteco.gob.es/es/prensa/ultimas-noticias/El-Plan-de-Medidas-ante-el-Reto-Demogr\%C3\%A1fico-destinar\%C3\%A1-m\%C3\%A1s-de-10.000-millones-y-130-pol\%C3\%ADticas-activas-a-luchar-contra-la-despoblaci\%C3\%B3n-y-garantizar-la-cohesi\%C3\%B3nterritorial-y-social/tcm:30-524061.

80 Ministerio para la Transición Ecológica y el Reto Demográfico, «El MiTECO y la FEMP acuerdan una mayor participación de las entidades locales en la gestión de los fondos del Plan de Recuperación, Transformación y Resiliencia icono barra herramientas", 11 de marzo de 2021, https://www.miteco.gob.es/es/ prensalultimas-noticias/El-MITECO-y-la-FEMP-acuerdan-una-mayor-participaci\%C3\%B3n-de-las-entidadeslocales-en-la-gesti\%C3\%B3n-de-los-fondos-del-Plan-de-Recuperaci\%C3\%B3n-Transformaci\%C3\%B3n-y-Resiliencialtcm:30-523853.

Comparecencia del secretario general Francisco Boya, Cortes Generales, Diario de Sesiones, Senado, XIV Legislatura, núm. 166, 17 de marzo de 2021, p. 15, https://www.senado.es/legis14/publicaciones/pdflsenado/ds/ DS_C_14_166.PDF.

81 Ministerio para la Transición Ecológica y el Reto Demográfico, «Manifestación de interés. Plan de recuperación, transformación y resiliencia. Proyectos tractores para afrontar el reto demográfico y la lucha contra la despoblación", https://www.miteco.gob.es/es/reto-demografico/temas/manifestacion_interes_reto_demografico_tcm30-517778.pdf. 
mente desde la sociedad civil y las empresas. Dicho de otro modo, si bien el mundo local tradicionalmente se queja del exceso de iniciativas de arriba-abajo, este tipo de expresiones de interés para el MRR casi pecaban de lo opuesto ${ }^{82}$.

\section{El ejemplo de la Mesa Nacional Técnica de Diputaciones}

Además de la propia incertidumbre al respeto de la cascada de anuncios, a menudo contradictorios sobre el plan de recuperación, el retraso de la pandemia en aprobar los reglamentos de los Fondos Estructurales — cuyo diálogo informal entre Comisión y Gobierno central había comenzado ya en la primavera 2019-, y dada la necesidad de identificar el posible encaje de las administraciones locales y en concreto las diputaciones provinciales en los Fondos Estructurales 2021-2027 como en el MRR, la Diputación de Zamora convocó la llamada Mesa Nacional Técnica de Diputaciones.

Un factor desencadenante de este ejercicio fue el entonces inminente acuerdo sobre nuevo Reglamento del fondo FEDER 2021-2027, donde por primera vez se define qué es un territorio afectado por el declive demográfico (precisamente a nivel provincial) y, por tanto, mereciente de un tratamiento prioritario y específico en los programas 20212027, un tema de particular interés en España y de hecho el resultado de una movilización a nivel europeo, fundamentalmente de actores españoles ${ }^{83}$.

A pesar de la incertidumbre por la falta de concreción en el borrador del Plan España Puede como el real decreto-ley sobre el rol de las diputaciones en el MRR — el MRR no lo impide y de hecho su antecesor el SRSP ha financiado varios procesos modernizadores de la planta local, por ejemplo- , se estimó necesario poder adelantarse a los acontecimientos y al menos identificar necesidades en base a la experiencia de la gestión anterior de Fondos Europeos por las diputaciones y en base a los documentos de referencia conocidos a la altura de octubre de 2020.

${ }^{82}$ La nota anterior del MITECO indica que de las más de 4.200 iniciativas recibidas, más del 60 por 100 procedían de pequeños ayuntamientos, lo que ha permitido acercar el Plan de Medidas a la administración local y orientar de manera eficaz sus actuaciones hacia los pequeños municipios.

83 Dicha definición estima que se deben priorizar las provincias o ayuntamientos tengan menos de 12,5 habitantes por $\mathrm{km}^{2}$ o que hayan sufrido un descenso demográfico interanual superior al 1 por 100 durante 2007-2017 (cdo. 45) y que deben ser objeto de planes específicos y financiación prioritaria con cargo a los fondos FEDER (art. 8 bis FEDER 2021-2027).

Cfr. CONSEJO DE LA UE, «European Regional Development Fund and Cohesion Fund (ERDF/CF) Regulation - Analysis of the final compromise text with a view to agreement», 6181/21, Brussels, 25 de febrero de 2021. Este autor fue sido precisamente el redactor e impulsor de la misma, vid. M. SOSA TrOYA, «La UE prioriza la despoblación en los fondos Feder con una definición de la que se beneficiará España», El País, 10 de diciembre de 2020; S. PAZOS-VIDAL, "Reto Demográfico», Agenda Pública, 7 de abril de 2019, https://agendapublica.es/reto-demografico/; M. MolinA IBÁN̄EZ, «Dimensión territorial de la despoblación: Aproximación al papel de las políticas públicas en un entorno europeo», en J. Farinós Dasí, J. F. OJeda Rivera y J. M. Trillo SANTAmaría (eds.), España: Geografias por un Estado posmoderno, AGE/Geocrítica, Madrid-Barcelona, 2019. 
De hecho, no era la primera vez que se intentaba hacer este ejercicio; ya en febrero de $2018^{84}$, la Comisión de Presidentes de Diputaciones y Cabildos de la FEMP había acordado una resolución para iniciar esos trabajos, sin que tuviese solución de continuidad.

El 13 de octubre de 2020, y bajo el patronazgo de la Diputación de Zamora, la Jornada Nacional de Despoblación del 13 de octubre de 2020 reunió a técnicos en despoblación/reto demográfico de 21 diputaciones provinciales ${ }^{85}$.

Como resultado de dicho encuentro se crearon seis grupos de trabajo (facilitados por el autor) en los que los técnicos en su mayoría responsables o miembros de los departamentos o servicios de diputaciones que gestionan proyectos europeos examinaron, en base a su experiencia en la gestión de dichos programas e independientemente de su filiación profesional, las posibilidades de orientar los Fondos Estructurales 2021-2027 y el Mecanismo de Recuperación y Resiliencia (Plan España Puede) con el fin de hacer frente al fenómeno de la despoblación y teniendo en cuenta el papel que las diputaciones pueden desempeñar en el próximo periodo de programación que comienza en 2021.

Los grupos de trabajo se estructuraron con base en las prioridades temáticas identificadas como más relevantes para el nivel local y provincial y en concreto aquellas zonas con declive demográfico, tanto por el ya citado Anexo D, que es la base de la negociación Comisión-España para el Acuerdo de Asociación 2021-2027 como el propio borrador del Plan España Puede. En línea con lo que se pretende con el MRR, criterios de identificación de prioridades y proyectos se basaron en criterios de escalabilidad, replicabilidad, eficacia (ya demostrada a menor escala o realísticamente esperable de existir financiación).

El objetivo fue el diseño de un borrador de programa interprovincial contra la despoblación financiable con Fondos Estructurales y/o MRR y que pusiese en valor las competencias y saber hacer de diputaciones como actores del territorio. Dicho lo cual no se prejuzgó ex ante el encaje final de dichas recomendaciones, ya que dependiendo del eventual uso de las mismas por los decisores políticos podrían también ser la base para prioridad específica dentro del Plan de recuperación, un Programa Operativo FEDERFSE Interprovincial, actuaciones dentro del Programa INTERREG (ya se prevé eje específico de reto demográfico en el Programa España-Portugal POPTEP), como la propia subdelegación de fondos en los Programas operativos autonómicos del FEDER, FSE y FEADER.

${ }^{84}$ Cfr. «La FEMP exige que las diputaciones gestionen fondos europeos ante el reto demográfico», Soria Noticias, 13 de febrero de 2018, https://sorianoticias.com/noticia/2018-02-13-la-femp-exigira-ue-que-diputaciones-gestionen-fondos-europeos-reto-demografico-46118.

${ }_{85}$ Todos los técnicos eran jefes de servicio, o cargo equivalente, dedicados a fondos europeos con más de diez años de experiencia y participaron a título personal procedían de las diputaciones. Málaga, Albacete, Ourense, Zamora, Granada, Palencia, Burgos, Córdoba, Castellón, Ciudad Real, Salamanca, Palencia, Valladolid, Teruel y Badajoz. 
Este documento, elaborado en dos reuniones de cada grupo, un plenario intermedio el 15 de diciembre fue finalizado en reunión plenaria de 15 de diciembre de $2020^{86}$. A partir de ese momento los técnicos de las diputaciones reunidas acordaron elevarlo a sus órganos de gobierno y adjuntarlo a las respectivas contribuciones a las manifestaciones de interés de cada ministerio, empezando por la del reto demográfico.

Las conclusiones más importantes de estos trabajos fue el hecho de que un gran número de técnicos de las diferentes diputaciones nunca se habían reunido - en ese aspecto la pandemia ha jugado a favor ya que todas la reuniones fueron telemáticas- y no eran conscientes del saber hacer y la transferibilidad de las experiencias de unas a otras. Por ejemplo, la Diputación de Cuenca había desarrollado un portal de administración digital que es perfectamente replicable en otras administraciones $-\mathrm{y}$ de hecho alguna de otra Comunidad ya lo había adoptado - pero era desconocida por el resto de diputaciones.

El otro gran dilema fue el rol de las diputaciones respecto a las otras administraciones y entidades. Respecto a las Comunidades Autónomas surgieron dudas sobre todo en lo relativo a la posibilidad práctica, jurídica (y política) para que varias diputaciones de Comunidades diferentes pudiesen cooperar entre sí. También surgían dudas respecto al rol y legitimidad de las diputaciones para realizar proyectos en aquellos ayuntamientos de más de 5.000 habitantes. Igualmente un tema no menor es la situación de desventaja percibida por las diputaciones a la hora de proveer o ayudar a la provisión de servicios y bienes públicos que estén sujetos a licitaciones a nivel estatal —como, p. ej., los planes de expansión a banda ancha de las grandes operadoras de telecomunicaciones-.

En este sentido, el sentimiento generalizado es el esfuerzo innecesario que (a juicio de los técnicos de las diputaciones) supone las convocatorias competitivas de proyectos a nivel nacional, sobre todo en la medida que buena parte de proyectos se podrían establecer de manera colaborativa y replicable entre varias diputaciones como los identificados en la Tabla III (vid. infra). Se constató la necesidad de sobrepasar los proyectos aislados y dotarlos de un carácter integrado.

Para ello, la arquitectura de los fondos y su desarrollo a nivel nacional o autonómico genera toda una serie de silos que dificultan que las diputaciones como actores del territorio provincial sean capaces de llevar a cabo actuaciones integradas. Y ello a pesar de que existía un consenso amplio que las actividades identificadas por este grupo de técnicos de diputaciones serían financiables igualmente por medio de los Fondos Estructurales y por el MRR.

${ }^{86}$ En el caso de Zamora, Diputación de Zamora, «12. Moción conjunta del Grupo Popular y Grupo Mixto para instar al Ministerio para la Transición Ecológica y el Reto Demográfico, a que sean tenidas en cuenta las recomendaciones de la Diputación Provincial de Zamora respecto al futuro reparto de Fondos Europeos Post 2020», expediente 111/2021, 15 de enero de 2021. 
TABLA III. PRINCIPALES RECOMENDACIONES DE LA MESA NACIONAL DE DIPUTACIONES PARA ACTIVIDADES COLABORATIVAS FINANCIADAS A CARGO DEL MRR Y FONDOS ESTRUCTURALES

\begin{tabular}{|c|c|}
\hline Servicios básicos & Servicios públicos \\
\hline $\begin{array}{l}\text { - Asistencia y cooperación a los ayuntamien- } \\
\text { tos más pequeños, en particular a los de } \\
\text { menos de } 5.000 \text { habitantes y en sus ámbitos } \\
\text { competenciales propios (viales, movilidad, } \\
\text { TIC, y también en servicios asistenciales y } \\
\text { de cooperación local). } \\
\text { - Servicios Sociales: desarrollo y mejora de sis- } \\
\text { temas monitorización y teleasistencia de la } \\
\text { población mayor particularmente en el ám- } \\
\text { bito rural. } \\
\text { - Residuos Sólidos Urbanos (RSU) (com- } \\
\text { postaje, separación de residuos, sensórica). } \\
\text { Sistemas de monitorización de las cargas de } \\
\text { contenedores para mejorar la eficiencia de } \\
\text { las rutas de recogida). } \\
\text { - Eficiencia energética; programas provinciales } \\
\text { en edificios públicos (sensórica y cambio de } \\
\text { luminarias a LED, calefacción con biomasa } \\
\text { y geotérmica), parque móvil (puntos de re- } \\
\text { carga y cambio del parque móvil municipal). } \\
\text { Aguas, bombeos (ahorro energético median- } \\
\text { te energía solar para el bombeo de agua y la } \\
\text { depuración como ozonización, etc.), depu- } \\
\text { ración y saneamiento de pequeños núcleos. } \\
\text { - Lucha contra Incendios (infraestructuras, } \\
\text { equipamientos, Epis, etc.). } \\
\text { - Apoyo a ayuntamientos de pequeñas pobla- } \\
\text { ciones adquieran y rehabiliten edificios para } \\
\text { destinarlos a alquiler para nuevos poblado- } \\
\text { res, o jóvenes que quieran quedarse en el } \\
\text { territorio, como primera residencia y a un } \\
\text { precio tasado máximo asequible. }\end{array}$ & $\begin{array}{l}\text { - Gran potencial y experiencia probada y re- } \\
\text { plicable por parte de varias diputaciones } \\
\text { en la creación y provisión para sus propios } \\
\text { ayuntamientos y otras diputaciones de Pla- } \\
\text { taformas de Administración Electrónica; } \\
\text { (encomiendas de contratación de los ayunta- } \\
\text { mientos, centrales de contratación, Platafor- } \\
\text { mas de consumo, tributos, seguimientos de } \\
\text { expedientes, etc.). Potencial optimización de } \\
\text { las plataformas de diputaciones ya existentes } \\
\text { y hacerlas escalables al conjunto de España. } \\
\text { - Los fondos FEDER, pero sobre todo el Plan } \\
\text { de Recuperación tiene la modernización y } \\
\text { digitalización de servicios públicos como } \\
\text { punta de lanza ya que la Comisión Europea } \\
\text { estima que con una administración digital es } \\
\text { más fácil desarrollar las otras actividades de } \\
\text { fomento económico y sostenibilidad. } \\
\text { - Creación de programas gestionados por las } \\
\text { diputaciones para la digitalización y moder- } \\
\text { nización de servicios de los ayuntamientos } \\
\text { más pequeños, potencialmente de forma } \\
\text { mancomunada con otras diputaciones de } \\
\text { toda España, como a mucha menor escala. } \\
\text { Este ya ha sido el caso en otros países con } \\
\text { cargo al programa ISA2 de la UE. }\end{array}$ \\
\hline Conectividad & Actividad empresarial y empleo verde \\
\hline $\begin{array}{l}\text { - Financiación de la puesta en marcha de } \\
\text { Servicios digitales básicos como la teleasis- } \\
\text { tencia precisa incluida la generalización de } \\
\text { banda ancha de calidad. }\end{array}$ & $\begin{array}{l}\text { Las diputaciones tienen amplia experiencia } \\
\text { en la provisión con cargo al FEDER y FSE de } \\
\text { agentes dinamizadores de emprendimiento y } \\
\text { la innovación rural, por lo que es enteramente } \\
\text { posible desarrollar estos proyectos y dotarles de } \\
\text { escalabilidad que los conviertan en programas } \\
\text { transformadores de carácter estructural: }\end{array}$ \\
\hline
\end{tabular}


- El rol de las diputaciones tiene que ir de mano de las autoridades nacionales y las operadoras y concesionarias de la banda ancha para asegurar una extensión previsible y financieramente sostenible. Se debería articular una colaboración entre diputaciones y operadoras para poder planificar el despliegue de banda ancha a nivel nacional. Tanto el FEDER como el MRR podrían financiar la obra civil básica provista por las diputaciones que permitiese la instalación de servicios de telecomunicaciones por los diferentes proveedores, particularmente en los pueblos pequeños y aislados (conocido como la última milla).

- Del mismo modo, tanto FEDER como sobre todo el MRR permiten la elegibilidad de infraestructura básica (carreteras, viales) de competencia de las diputaciones siempre que se enmarque en los objetivos marcados por los Reglamentos Europeos y los correspondientes planes nacionales.
- Fomento del emprendimiento social.

- Ampliación del espectro de los programas para colectivos específicos, ya que el medio rural ya tiene de por sí esa necesidad diferenciadora, como, por ejemplo aquellos colectivos que no son jóvenes (Iniciativa de Empleo Juvenil) pero que tienen la capacidad, recursos y madurez para emprender, y que actualmente excluidos por los fondos UE.

- Fomento de la microfinanciación.

- Fomento de la transferencia de negocios.

- Emprendimiento de ciclo completo: «Formación, Asesoramiento, Acompañamiento, Financiación de proyectos de inversión». En otros países de la UE a pesar de las limitaciones del Fondo Social Europeo para apoyar más de una ocasión a un beneficiario, se han podido diseñar con el aval de la Comisión Europea dichos programas integrados que permiten el apoyo continuo de un beneficiario desde la exclusión sociolaboral a la formación, búsqueda, obtención y retención de un empleo.

- Apoyar la relocalización empresarial, asentar a los jóvenes talentos en el territorio, luchar contra el abandono rural fomentando la puesta en marcha de proyectos innovadores generadores de desarrollo sostenible, tanto en el sector primario como en el ámbito de la economía verde y azul en las zonas costeras.

Fuente: elaboración propia a base del documento Recomendaciones de la Jornada Nacional Técnica de Diputaciones Provinciales respecto al uso de los Fondos Europeos post 2020 para combatir el reto demográfico, Zamora, 15 de diciembre de 2020.

Por otro lado, se valoró positivamente que el Real Decreto-ley 36/2020 se permite la otorgación de subvenciones de concurrencia no competitiva (art. 62 del real decretoley), con cargo al Fondo de Recuperación, para aquellas subvenciones cuyo objeto sea financiar actuaciones o situaciones concretas que no requieran de valoración comparativa con otras propuestas.

Sin embargo, las diputaciones consideran que han sufrido limitaciones presupuestarias en los últimos años que ha provocado una limitada capacidad de adelantar recursos propios a las inversiones de Fondos Estructurales, así como aportar cofinan- 
ciación. Por tanto, nada impediría en los Reglamentos de la UE que Comunidades o ministerios provean la cofinanciación a las diputaciones, como así ha sucedido en el pasado en algunas provincias. En este sentido, cabe señalar que el real decretoley permite facilitar la contratación de personal laboral para agilizar la gestión de fondos.

En ese sentido y al hilo del riesgo ya citado de que sea Hacienda también la autoridad de gestión del MRR, además de para los Fondos Estructurales se evocó que por su falta de medios humanos, su lentitud en la gestión de los proyectos cofinanciados ha constituido, a juicio de varias diputaciones, un desincentivo a solicitar fondos de la UE.

También se ha detectado en algunos casos una insuficiente dotación de recursos humanos especializados, así como de unidades de gestión apropiadas en las diputaciones, lo que invita a hacer una reflexión sobre la necesidad de implementar estructuras más operativas con capacidades y competencias suficientes para acometer estos fines en materia de despoblación, emprendimiento o digitalización.

Por último, surgieron bastantes dudas en lo relativo a las «Oficinas para la lucha contra la despoblación» previstas tanto por la llamada Agenda para el Cambio como las ya citadas Directrices contra el Reto Demográfico aprobadas por el Consejo de Ministros, que serían susceptibles de ser financiadas con los fondos europeos. De hecho, ya se han lanzado en algunas provincias como Huesca o Castellón, sin que estén bien claros los criterios para tal decisión. En ese sentido existió un consenso a reivindicar que desde su constitución las diputaciones son las estructuras administrativas intermedias que aseguran el equilibrio territorial. En muchas provincias las diputaciones facilitan la coordinación y cooperación entre las distintas estructuras administrativas locales, mancomunidades y Grupos de Desarrollo Local.

Concretamente, antecedentes de creación de oficinas similares financiadas con fondos europeos sugieren que cuando no se apoyan en las estructuras administrativas de las diputaciones, apoyando las iniciativas transversales de la institución provincial e insertas en el ecosistema del territorio, evitando duplicidades con servicios existentes, este tipo de oficinas no sobreviven más allá de la subvención inicial. Esta falta de continuidad resulta en la consecuente pérdida del saber hacer acumulado ${ }^{87}$.

Por ello, las conclusiones de la llamada Mesa Nacional de Diputaciones piden se considere el establecimiento de dichas Oficinas de Atención al Despoblamiento en Programas Específicos con una estrategia definida e integradas en los servicios de la diputación provincial correspondiente.

87 Para ejemplo el destino de las Oficinas Comarcales de Galicia, vid. J. A. CARIDAD GraÑA, El proceso histórico del desarrollo comarcal de Galicia, Tesis Doctoral, Universidade da Coruña, 2012. 


\section{CONCLUSIONES: PERSPECTIVAS DE LAS ADMINISTRACIONES LOCALES EN LOS FONDOS EUROPEOS POST 2020}

Este documento acordado conjuntamente por técnicos de 30 diputaciones fue aprobado al menos por el Pleno o Junta de Gobierno de tres diputaciones - Zamora, Ourense y Guadalajara-, a la vez que se ha remitido a las varias convocatorias de Reto Demográfico y otros ministerios para el MRR y fue presentada al secretario general de Reto Demográfico ${ }^{88}$.

El aspecto positivo de la llamada Mesa Nacional es que generó dinámicas colaborativas nuevas que luego se desenvolvieron autónomamente, pasando incluso del nivel técnico al político, notablemente la propuesta conjunta sobre los proyectos del área digital que fue acordada políticamente por 10 diputaciones para la convocatoria del MRR de Digitalización ${ }^{89}$.

Por otro lado, se aprecia una inercia entre las autoridades municipales y provinciales cara a la búsqueda de soluciones individualizadas. Si bien la FEMP ha acordado con el Ministerio de Transición Ecológica la asignación de fondos a nivel local y provincial (vid. supra), en el marco del ya citado Plan de Medidas ante el Reto Demográfico, parece que la lógica prevalente es la de utilización de foros colectivos como mero canal para captación de recursos individuales y no para la realización de proyectos colaborativos.

De hecho, la propia FEMP había propuesto un año antes, al comienzo de la crisis de la covid-19, el puro reparto del 14,16 por 100 de lo que recibiese España de la UE (equivalente al peso de las haciendas locales en el conjunto del gasto público) y que luego se repartiese entre las corporaciones simplemente por población ${ }^{90}$. Un año después, y al tiempo del acuerdo de FEMP con Transición Ecológica, los alcaldes de grandes ciudades exigían una cuota del MRR equivalente al porcentaje de las haciendas locales respecto del total del gasto público ${ }^{91}$, para presumiblemente repartirse del mismo modo que ya ha ocurrido con el EDUSI (que pasa del 5 al 8 por 100 del FEDER en 2021-2027) en vez de priorizar los proyectos colaborativos y de país.

Si bien los detalles del Plan de Recuperación y las convocatorias que emanen del mismo no son conocidos en el momento de la redacción de este artículo las propias

${ }^{88}$ M. Herrera, «La Diputación de Zamora pide a Reto Demográfico una lucha contra la despoblación desde el terreno", La Opinión de Zamora, 3 de febrero de 2021.

89 EUROPA PRESS, «Varias diputaciones provinciales se unen para reclamar fondos y mejorar la conectividad de sus territorios», 25 de febrero de 2021, https://www.europapress.es/castilla-y-leon/noticia-varias-diputaciones-provinciales-unen-reclamar-fondos-mejorar-conectividad-territorios-20210225141446. html.

90 FEMP, «Pilares Locales para la Reactivación Económica y Social de la Administración local». Federación Española de Municipios y Provincias. Documento aprobado por la Junta de Gobierno de la FEMP el día 22 de mayo de 2020», pp. 37-38, http://www.femp.es/sites/default/files/multimedialdocumento_aprobado_por_ unanimidad_femp_pilares_reactivacion_admon_local_22_mayo_2_0.pdf.

91 Pedían entre 14.000 y 30.000 millones, una vez más sin entrar en consideraciones si los costes serían elegibles en el marco de los Fondos de la UE. J. LlAMET, «Alcaldes de todos los partidos reclaman a Hacienda recibir al menos el 10 por 100 de los fondos europeos", El Mundo, 4 de marzo de 2021. 
administraciones autonómica y central parecen estar animando esta misma dinámica de reparto de fondos mediante concurrencia competitiva con el caso del REACT EU ${ }^{92}$ el propio MRR (primer reparto de 100 millones del MRR para saneamiento en ayuntamientos de menos de 5.000 habitantes) ${ }^{93}$.

Existen otras alternativas, como la gobernanza multinivel y los instrumentos de desarrollo territorial integrado que ya se usan en los Fondos Estructurales como los ITI y el CLLD ya citados — perfectamente adaptables al MRR_, como los convenios de Transición Justa (11 ya existentes que usarán el Fondo de Transición Justa, el MRR o los propios Fondos Estructurales y que vinculan al Ministerio de Transición Ecológica, las Comunidades Autónomas y los municipios concernidos, a través de la FEMP, para la diversificación y reconversión de los territorios en reconversión) ${ }^{94}$ se encarga la agencia Instituto de Transición Justa ${ }^{95}$, que también está intentando diseñar una estrategia para que estos pequeños ayuntamientos dentro de las provincias designadas como de Transición Justa en el Reglamento FTJ ${ }^{96}$ para los cuales dentro del Plan de Recuperación, Transformación y Resiliencia, en el componente de Transición Justa se ha incluido una línea de 100 millones de euros para infraestructuras municipales zonas de Transición Justa como laboratorios de innovación para otros componentes y realizar proyectos «piloto» que permitan un posterior escalado a través del Fondo de Transición Justa y otros fondos del Marco financiero plurianual 2021-2027 (FEDER) ${ }^{97}$. Lo lógico es que este tipo de iniciativas multinivel se extendiesen al resto de territorios.

Alternativamente, las llamadas oficinas de despoblación, o «hub de Innovación Rural», podrían constituir, como avanzaban las Directrices para la Estrategia contra el Reto Demográfico y el Plan recientemente anunciado, un centro neurálgico orientado al im-

92 Por ejemplo, así se desprende de las bases reguladoras para la concurrencia competitiva de los ayuntamientos gallegos para el fondo REACT: vid. Resolución de 12 de marzo de 2021, por la que se aprueban las bases reguladoras para la concesión de subvenciones a los ayuntamientos, en régimen de concurrencia competitiva, destinadas a la ejecución de obras de abastecimiento, saneamiento y depuración, financiadas en el marco del eje REACT-UE del programa operativo Feder Galicia 2014-2020, y se convocan para el año 2021, Diario Oficial de Galicia, núm. 56, 24 de marzo de 2021.

93 Cfr. «El Consejo de Ministros da luz verde al reparto territorial de los primeros 581 millones de euros del Plan de Recuperación, Transformación y Resiliencia como barra herramientas», 23 de marzo de 2021, https://www.miteco.gob.es/es/prensalultimas-noticias/el-consejo-de-ministros-da-luz-verde-al-reparto-territorial-delos-primeros-581-millones-de-euros-del-plan-de-recuperaci\% C3\%B3n-transformaci\% C3\% B3n-y-resiltcm:30524261.

94 Ministerio para la Transición Ecológica y el Reto Demográfico, «El MiteCO, el Gobierno de Andalucía y la FEMP firman los protocolos para elaborar los Convenios de Transición Justa para áreas de Almería, Cádiz y Córdoba», 9 de marzo de 2021.

95 Real Decreto 179/2021, de 23 de marzo, por el que se aprueba el Estatuto del Instituto para la Transición Justa.

96 Provincias de A Coruña, Cádiz, Almería, León, Burgos, Teruel, Córdoba y Principado de Asturias.

97 Ministerio de Transición Ecológica Instituto para la Transición Justa, "Consulta Pública Previa. Proyecto de normativa de las bases reguladoras del programa de ayudas a entidades locales del Plan de infraestructuras públicas en las zonas de transición justa en el marco del Plan de Recuperación, Transformación y Resiliencia», 2021. 
pulso de políticas que den respuesta al reto demográfico y que se financiará con cargo a los fondos europeos de reconstrucción podrían integrarse y trabajar en red para crear una inteligencia territorial compartida, pero es todavía pronto para afirmar si la joven Secretaría General de Reto Demográfico dará ese paso, habida cuenta los equilibrios interdepartamentales y la necesidad de cuidar las relaciones con las Comunidades Autónomas ${ }^{98}$.

En definitiva, existen recursos y existe interés desde el nivel local para asegurarse el máximo acceso tanto de los fondos del Plan de Recuperación como de los Fondos Estructurales tradicionales. El «laboratorio viviente» en red realizado por las ya citadas diputaciones es significativo por lo inusual en el marco español ${ }^{99}$. Es de temer que lo que falte sea también capacidad de gestión y absorción, y sobre todo coherencia y ambición para financiar de forma colaborativa proyectos escalables y realmente transformadores ${ }^{100}$.

Lo suyo sería que todos los fondos UE fuesen sujetos a un Marco Estratégico Común, con claras demarcaciones entre ellos y un papel claro de todos los niveles de gobierno, en función de sus competencias, en su definición, gestión y evaluación, aprendiendo de los fallos y los éxitos de treinta años de fondos europeos en España.

\section{BIBLIOGRAFÍA}

AdDIsON, H.: «Is Administrative Capacity a Useful Concept? Review of the Application, Meaning and Observation of Administrative Capacity in Political Science Literature», LSE Research Paper, 2009, http://personal.lse.ac.uk/addisonh/Papers/AC_Concept.pdf.

98 Así hay que entender el enfoque cauto adoptado por el nuevo Plan de 130 medidas contra el reto demográfico (p. 19) destinado a incitar a que la Conferencia de Presidentes acuerde la Estrategia Nacional del Reto Demográfico, mediante el trabajo previo de Conferencia Sectorial para el Reto Demográfico, que celebró su primera reunión el 23 de julio de 2020, y que permite articular las actuaciones del Estado y autonómicas de una manera integrada y que asegure la complementariedad de las medidas y, por otro, la participación de las Entidades locales en la gobernanza multinivel del reto demográfico a través de la Comisión Nacional de Administración Local (CNAL), y del grupo de trabajo sobre Reto Demográfico y Lucha contra la Despoblación.

99 Además, no parece que las Comunidades se vayan a comportar con los ayuntamientos de una forma más constructivo que lo que lo hace el Gobierno central en el marco del MRR. Para muestra un botón, el art. 9 del Decreto-ley 3/2021, de 3 de marzo, de medidas urgentes para la modernización de la Administración Pública y para la ejecución del Plan de Recuperación, Transformación y Resiliencia (Diario Oficial de Extremadura, 8 de marzo de 2021) no se da ningún rol particular a los ayuntamientos en el marco de sus competencias que los diferencia de universidades o la sociedad civil a la hora de discutir posibles proyectos de la Junta con cargo al MRR, cuando recientemente el Consejo de Política Local de Extremadura (COPLE), formado por la Junta y los representantes de los ayuntamientos, había precisamente acordado lo contrario.

100 En un sentido parecido, pero también más optimista, se pronuncian: R. JIMÉNEZ ASENSIO, «El papel de los gobiernos locales en los Planes de Recuperación y Resiliencia», La mirada institucional, 20 de enero de 2021, https://rafaeljimenezasensio.com/2021/01/20/papel-de-los-gobiernos-locales-en-los-planes-de-recuperacion-yresiliencial, así como M. Hidalgo, El papel clave de las entidades locales en los fondos europeos, https://www. vozpopuli.com/opinion/administraciones-locales-fondos-europeos. html. 
BACHTler, J., y MéndeZ, C.: "Who governs EU cohesion policy? Deconstructing the reforms of the structural funds», Journal of Common Market Studies, vol. 45, núm. 3, 2007, pp. 535-564.

Bachtler, J.; Méndez, C., y Wishdale, F.: «Will Cohesion Policy recover from covid? An Initial Assessment", European Regional Policy Research Consortium Paper 20/3, European Policies Research Centre, 2020.

BATET, M. P.: La urgencia y la emergencia en la tramitación de los fondos de recuperación, 21 de marzo de 2021, https://lapartecontratante.blog/2021/03/21/la-urgencia-y-la-emergencia-en-latramitacion-de-los-fondos-de-recuperacion-por-m-p-batet/.

Blanes. M. A.: La ocultación de las observaciones esenciales del Consejo de Estado al Real Decretoley sobre los Fondos Europeos y su posible inconstitucionalidad, 1 de marzo de 2021, https:// miguelangelblanes.com/2021/03/01/la-ocultacion-de-las-observaciones-esenciales-del-consejo-deestado-al-real-decreto-ley-sobre-los-fondos-europeos-y-su-posible-inconstitucionalidad/.

BuTI, M., y POLli, O.: "Veto player theory and the governance of the Recovery and Resilience Facility», VOXEU, 11 de febrero de 2021, https://voxeu.org/article/veto-player-theory-and-governance-recovery-and-resilience-facility.

CARIDAD GRaña J. A.: El proceso histórico del desarrollo comarcal de Galicia, Tesis Doctoral, Universidade da Coruña, 2012.

Carrera Hernández, F. J.: «Del Mecanismo Europeo de Estabilidad (MEDE) al nuevo Mecanismo de Recuperación y Resiliencia (MRR): ¿ Ha sido necesaria una pandemia para reforzar la solidaridad financiera en la Unión Europea?», Revista Española de Derecho Europeo, núm. 75, 2020, pp. 9-53.

D'Alfonso, A.: National ratification of the Own Resources Decision. State of play on 18 March 2021, European Parliament Members' Research Service PE 690.520, 2021.

De Gregorio Hurtado, S., y González Medina, M.: «Las EDUSI en el contexto de las políticas de regeneración urbana en España (1994-2018)», WPS Review International on Sustainable Housing and Urban Renewal: RI-SHUR, núm. 6, 2017, pp. 54-80.

FALUd, A.: "A historical institutionalist account of European spatial planning», Planning Perspectives, vol. 3, núm. 4, 2018, pp. 507-522.

Farole, T.; Goga, S., y IOnescu-Heroiu, M.: Rethinking Lagging Regions: Using Cohesion Policy to Deliver on the Potential of Europe's Regions, World Bank, Washington, 2018.

FEÁs, E.: "Las cifras del Plan de Recuperación para Europa», Análisis del Real Instituto Elcano (ARI), núm. 86, 2020.

— «Lo que sabemos, y lo que no, del Plan de Recuperación Enrique Feás», Vozpopuli, 2 de febrero de 2021, https://www.vozpopuli.com/opinion/bruselas-recuperacion-sanchez_0_1432656938.html.

FeATHERSTONe, K.: «Conditionality, Democracy and Institutional Weakness: the Euro-crisis Trilemma», Journal of Common Market Studies, vol. 54, núm. 9, 2016, pp. 48-64.

FERRY, M.; KAH, S., y BACHTLER, J.: «Integrated territorial development: new instruments -new results?», IQ-Net Thematic Paper, 42 (2), junio de 2018.

García Perea, P.; Millaruelo, A.; Mora Bajén, V. M., y Sánchez Carretero, C.: «El semestre europeo 2020 y las recomendaciones específicas para España», Boletín económico - Banco de España, núm. 3, 2020, pp. 129-147.

Hall, R.: "The Development of Regional Policy in the Process of European Integration: An Overview», en G. BIsChof (ed.), Regional Economic Development Compared: EU-Europe and the American South, Innsbruck University Press, Innsbruck, 2015, pp. 13-33.

HidALGO, M.: «El papel clave de las entidades locales en los fondos europeos», https://www.vozpopuli.com/opinion/administraciones-locales-fondos-europeos. html. 
Hooghe, L., y Marks, G.: «Unravelling the central state, but how? Types of multi-level governance», American Political Science Review, vol. 97, núm. 2, 2003, pp. 233-243.

Jiménez Asensio, R.: «El Reglamento (UE) del Mecanismo de Recuperación y Resiliencia: 7 Líneas-Fuerza y una Apostilla», https://rafaeljimenezasensio.com/2021/02/15/el-reglamento-uede-recuperacion-y-resiliencia-7-lineas-fuerza-y-una-apostillal.

- «El papel de los gobiernos locales en los Planes de Recuperación y Resiliencia», La mirada institucional, 20 de enero de 2021, https://rafaeljimenezasensio.com/2021/01/20/papel-de-losgobiernos-locales-en-los-planes-de-recuperacion-y-resiliencial.

Jiménez Asensio, R., y VÁzquez Matilla, F. J.: «La carrera por los fondos europeos», El Confidencial, 26 de enero de 2021.

KAH, S.: «Implementing ERDF Through CLLD: Experiences So Far», European Structural and Investment Funds Journal, vol. 7, núm. 1, 2019, pp. 47-57.

KÖLling, M.: «El Consejo Europeo extraordinario del 17 al 20 de julio de 2020: mucho ruido, muchas nueces y algunas sombras», Análisis del Real Instituto Elcano (ARI), núm. 100, 2020.

LLAMET, J.: "Alcaldes de todos los partidos reclaman a Hacienda recibir al menos el 10 por 100 de los fondos europeos», El Mundo, 4 de marzo de 2021.

Longo, F.; Del Pino Matute, E., y Lapuente, V.: «Por un sector público capaz de liderar la recuperación», Agenda Pública, 2 de junio de 2020, https://agendapublica.es/por-un-sectorpublico-capaz-de-liderar-la-recuperacion/.

LÓPEZ GARrido, D.: «La silenciosa constitucionalización de la Unión Europea», Revista de las Cortes Generales, núm. 109, 2020, pp. 187-208.

Molica, F., y Lleal FonTÀs, E.: “"Next Generation EU”: a threat to Cohesion Policy?», Technical note, Conference of Peripheral Maritime Regions, diciembre de 2020.

Molina IBÁÑEZ, M.: «Dimensión territorial de la despoblación: Aproximación al papel de las políticas públicas en un entorno europeo», en J. FARINÓS DASÍ, J. F. OJEDA Rivera y J. M. Trillo Santamaría (eds.), España: Geografías por un Estado posmoderno, AGE/Geocrítica, Madrid-Barcelona, 2019.

Otero Iglesias, M.: «Europe’s Coronavirus Identity Crisis», Politico, 1 de abril de 2020, https:// www.politico.eu/articleleuropes-coronavirus-pandemic-economic-identity-crisis-corona-bonds/.

PAZOS-VIDAL, S.: Partnership Agreements CEMR Survey Report on Involvement of national associations of LRAs in the Partnership Agreement preparations, Council of European Municipalities and Regions, 2013.

- "The Partnership Principle in Cohesion Policy 2014-2020 Breaking New Ground in MultiLevel Governance?», European Structural and Investment Funds Journal, vol. 2, núm. 4, 2014, pp. 277-288.

- Subsidiarity and EU Multilevel Governance. Actors, Networks and Agendas, Routledge, Abingdon, 2019.

— «Reto Demográfico», Agenda Pública, 7 de abril de 2019, https://agendapublica.es/reto-demograficol.

— «Transición Justa y Fondos Europeos», Agenda Pública, 15 de enero de 2020, https://agendapublica.es/transicion-justa-y-fondos-europeos/.

- «Presupuesto Europeo, Regiones y Agricultura», Agenda Pública, 27 de febrero de 2020, http:/lagendapublica.elpais.com/presupuesto-europeo-regiones-y-agricultural.

— "REACT EU and Reality», Agenda Pública, 17 de junio de 2020, http:/lagendapublica.elpais. com/react-eu-and-reality/.

- «El coronavirus como test de resistencia de la integración europea: límites del diálogo constitucional», Eunomía: Revista en Cultura de la Legalidad, núm. 19, 2020, pp. 154-183. 
— «Rethinking governance after the covid-19 crisis: challenges and opportunities for power devolution and self-government", Rethinking governance after the covid-19 crisis - Post-Covid Europe Coppieters Foundation, 2021.

RAMIÓ, C.: «La reforma administrativa para la gestión de los fondos europeos. ¿’A la segunda la vencida? (I)», EsPúblico, 3 de febrero de 2021, https://www.administracionpublica.com/lareforma-administrativa-para-la-gestion-de-los-fondos-europeos-a-la-segunda-la-vencida-i/.

Rodríguez-Pose, A., y Garcilazo, E.: "Quality of Government and the Returns of Investment: Examining the Impact of Cohesion Expenditure in European Regions», Regional Studies, vol. 49, núm. 8, 2015, pp. 1274-1290 (esp. p. 1274).

Roldán, T.: «Poisonous politics lurk behind the EU recovery fund», Financial Times, 20 de diciembre de 2020.

SÁNCHeZ, P.: «El primer PERTE de España: el coche eléctrico, El País, 7 de marzo de 2021.

Sosa Troya, M.: «La UE prioriza la despoblación en los fondos Feder con una definición de la que se beneficiará España», El País, 10 de diciembre de 2020.

TAPiA HermidA, A. J.:, «El plan de inversión que cambiará Europa y España en el próximo sexenio: el instrumento de recuperación de la Unión Europea y el Plan de Recuperación, Transformación y Resiliencia de España», La Ley Unión Europea, núm. 88, 2021.

XIFRÉ, R.:. «El plan NGEU en España: retos estructurales y revisión de propuestas», Cuadernos de Información Económica, núm. 279, 2020, pp. 11-20.

Zeitlin, J., y VANHERCKe, B.: «Socializing the European Semester: EU social and economic policy co-ordination in crisis and beyond", Journal of European Public Policy, vol. 25, núm. 2, 2018, pp. 149-174. 
